\title{
Setting of Gradient Material Properties and Quality Control of High Tension 3D NVEB-Weld Joints
}

\author{
Melanie Diebel ${ }^{1, a}$, Gregor Mroz ${ }^{1, b}$, Wojciech Frackowiak ${ }^{1, c}$, Jasmin Hauer ${ }^{1, d}$, \\ Wilfried Reimche ${ }^{1, \mathrm{e}}$ and Friedrich-Wilhelm Bach $^{1, \mathrm{f}}$ \\ ${ }^{1}$ Institute of Materials Science (IW), Leibniz University Hanover (LUH), \\ An der Universität 2, 30823 Garbsen, Germany \\ adiebel@iw.uni-hannover.de, ${ }^{b}$ mroz@iw.uni-hannover.de, ${ }^{c}$ frackowiak@iw.uni-hannover.de,

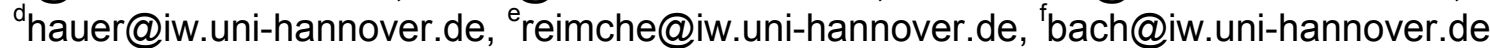

Keywords: stress-strain component design, gradient material properties, local heat treatment, beam technologies, non-vacuum-electron-beam-welding process, beam positioning, process control, anisotropy, global strengthening and hardening, strength and deformation properties of material, delayed crack growth, recrystallisation, weld joints integrity test, quality control, remote field eddy-current technology, weld-pool monitoring

\begin{abstract}
In modern, highly loaded structures of metallic materials, particular standards are required both regarding the strength and deformation properties of individual components as well as in terms of the load carrying capacity of the bonded joints between individual components. This specific subject matter is taken up in the subproject C4 "Setting of Gradient Material Properties and Quality Control of High Tension 3D NVEB-Weld Joints" within the framework of "Collaborative Research Centre" CRC 675 "High strength, locally modified components and structures" in order to correspondingly and individually adapt a component's properties to the loading profile. For this purpose, components having specifically calibrated strength properties are joined into high quality structures. Although still quite new but powerful, and due primarily to its very favourable welding characteristics, the non-vacuum electron beam welding technology is, in this case, to be further developed with respect to an improvement in beam positioning and weld-seam defect inspection.

On the other hand, a well-defined, local heat-treatment is to be carried out on individual, workhardened components to be able to introduce targeted and structured local, load-oriented microstructural changes into the component: thereby locally changing the component's strength and deformation properties with a view to retarding crack growth.
\end{abstract}

\section{Introduction}

Today's technical products and equipment are subject to increasing cost pressures whilst technical demands are steadily increasing. This development results from, among other things, international competition, which is constantly becoming tougher, in combination with globalised markets.

In this situation, components and structures which can better exploit materials by having higher load carrying capacities and good fail-safe properties for the same material and design expenditures lead to improved economic efficiency. Up to now, the use of different structural materials in one component are well-know, particularly in the form of composites such as fibre reinforced and sintered materials or as bonded semi-finished products in the form of tailored blanks or engineered blanks.

Important fields of development in the area of modern joining technology of high strength graded materials are, besides setting of stress-strain optimised microstructures for high strengths with sufficient ductility, to achieve a developed weld-seam as defect-free as possible. This mainly involves avoiding fusion defects in the weld's seam and root regions, aiming for zero porosity as well as avoiding crack formation in the seam and in the heat affected zone since these defects lead to failure of the welded joint, particularly under dynamic loading. 
Currently, there are only a few approaches in the area of post-processing steel components to precisely calibrate local material properties [1,2]. Most components are subject to functional surfaces or are completely post-processed in order, for example, to design wear resistant component surfaces or edge regions by means of hardening. Targeted local heat treating components for setting of graded, structured material properties are hitherto not recorded in the literature. Here, modern beam technologies provide new possibilities for specifically setting gradient material properties, which are optimised for stress-strain states, by means of partial and structured heat treatments whose potential is closely investigated with regard to increasing strength and ductility without initiating cracks.

\section{State of the art}

Manufacturing high quality welded joints. NVEB-welding is employed in the subproject C4 to manufacture high quality welded joints. Using this technology, both thin and thick walled components can be joined by means of low energy input per unit length and therefore produce narrow weld and heat affected zones. This welding procedure is qualified by high welding rates, a high overall efficiency of 40 to $50 \%$, good gap-bridging ability and high process tolerance by virtue of the widening of the beam and the tun-around time since no evacuation of the weld region is necessary [3]. The operating principle of the NVEB equipment can be employed for the quality control. During the welding process, a part of the electron's energy in the heating beam is transformed into secondary electrons and X-rays which can be measured and evaluated by means of the electron- and X-ray-detector measuring system, which was developed in the subproject C4.

Weld gap contour tracking. Owing to the boundary conditions, only electromagnetic measuring techniques having a sufficiently high measuring sensitivity, compared to material cutting, for electrically conducting and ferromagnetic materials and are suitable for detecting and tracking the weld-gap online in the process sequence to precisely track the beam-head during the laser and electron-beam welding. The initial approach for recognising the joint-gap in vacuum electron beam welding was described in [4]. In that case however, gap recognition was carried out via the electron beam itself by means of measuring the electrons' and X-ray's scattered radiation. An online inspection technique utilising beam deflection and evaluating the reflected electron-scattering was described by [5]. This is, however, exclusively applicable to vacuum electron beam welding. Neither procedure is applicable to NVEB welding owing to the beam control. Tracking the weldinggap's contour by means of optical and laser-optical techniques yield unsatisfactory positioning accuracy due to both the modified surface and reflective properties as well as the geometric relationships at the cut edges [5]. Owing to differing materials, residual stress states, edge misalignments and chamfering, the application of ultrasonic testing techniques also provides unsatisfactory measuring accuracy [6]. The comprehensive overview of applications and an assessment of electron beam welding by [7] deals primarily with the process control for welding aluminium and does not consider deviations in the seam-run. Based on $30 \mathrm{kV}$ equipment, the seam tracking system of [8], in which the reflections of the beta scatter beam is also recorded using detectors, requires a very accurate process control and is attended by a time delay since the electron beam is used as the energy source. For this reason, this matter requires further development as mentioned in [9]. Here, fundamental investigations into adaptive beam tracking were described which also utilises the reflected electron-scattering produced by the welding process as an information carrier. The seam run can be specified by means of a program for the beam-head. In this respect, the need for research exists regarding the processable component's thickness which is currently limited to a maximum of $5 \mathrm{~mm}$.

Process monitoring. Real-time process monitoring by means of temperature measurements at the weld-pool surface was utilised by [10] during laser conductive welding. The suitability of this optical system, which has two-colour digital cameras, has not yet been proven for the electron beam technology. 
In [11], WIG-welding processes are investigated using digital image processing in which the radiation emitted by the electric arc was evaluated. On the one hand, the weld pool itself was not the subject of the investigation and, on the other, no verification of the applicability to other beamwelding technologies was proposed.

By exploiting process-intrinsic effects, like the reflected scattering of primary electrons, the liberation of secondary electrons and roentgenbremsstrahlung produced from the component's edge region, techniques for radiographically analysing weld-pools provide the possibility of integrally characterising the welding processes [12]. The suitability of these types of testing techniques during vacuum electron beam welding was also investigated in [13]. Due to the widened and slightly diffuse electron beam in NVEB-welding, these results from the vacuum conditions are not easily translated. An application to the NVEB process has not hitherto been described in the literature.

Investigations on welded joints in light-metal components have previously been carried out to record radiation emissions from the weld-pool [14]. Their objective was to characterise the welding process by means of the infrared radiation emitted from the keyhole. This objective is still highly relevant and is also a subject of the current application for subproject $\mathrm{C} 4$. The main emphasis of the previous investigations was the manufacture of automotive, lightweight frame structures from pressure die-cast aluminium alloys which were welded under vacuum conditions using electron beam and laser technologies. By employing an infrared sensor, which detected the surface of the welding-pool, the emitted heat radiation was recorded and evaluated. In addition to this, the penetration current (electron flow) was synchronously measured. The correlation of both signal curves enabled the initial approaches for recognising the irregularity of the welding seam in the process overruns. Regarding the feed rates and the local resolution, the results of the investigations were, however, still not satisfactory. On the contrary, the analysis of the structure, which was already completely welded, had already been investigated by means of optically excited impulsethermography. Here, the laser beam welding method for butt-joints (I-seams) was employed as the joining technology [15]. Information on the types of defects, their sizes and the precise depths were not published.

Quality inspection of the welded joint. To assess the quality with regard to the strength properties of the welded seams, carried out on semi-finished products, the potential for developing online quality-controls of the welding process are investigated using different sources in the literature $[7,16]$. This is seen as absolutely essential, in particular for the industrial manufacture of semi-finished products. However, the publications only indicate the developmental path to pursue; serious investigations of the topic have still not been undertaken. Laser-based camera systems attain sufficient feed rates for scanning the welded-seam; however, only surface defects of no less than $0.5 \mathrm{~mm}$ diameter can be detected [17].

It is demonstrated in [18] that the NVEB-welding method is capable of high feed rates and thinwalled components. Using aluminium alloys as examples, it was verified that strength values adjacent to the seam of aluminium sheet components, welded with and without filling material, attain comparable values to those of the parent materials. The seam geometry as well as the strengths and ductility values can be specifically influenced by the filling material used. The method can be further developed with a view to steel materials as well a regarding thick-walled components.

To assess the quality of beam-welded seams, both the magnetic flux leakage and the multifrequency eddy current techniques were investigated by means of magnetic-field measuring sensors [19]. It was possible to detect non-metallic inclusions and concealed defects within the weldedseam volume as well as in the interior of multi-layered and thick-walled non-ferromagnetic components.

Setting of gradient material properties. Beam technologies such as laser and electron beam methods are currently employed to modify the edge-region properties of components. Local heat treatment produces an influence particularly on the strength and hardness properties, on the wear resistance and the toughness in order to match the properties to the required stress-strain levels. The 
change in the material properties is achieved without changing the chemical composition. Apart from the thermal residual stresses, the stresses occurring due to the microstructural transformation in heat treated steel are also taken into account [20].

[21] Describes how the desired microstructural properties in the component's edge-region are locally calibrated by using the beam-methods with very high energy densities. For this reason, the beam hardness already belongs to the state of the art; which is confirmed by a series of important publications

The multi-passing technique using the combined process steps: remelting, hardening and tempering of the component's edge region is described in [22]. By means of this method, internal component stresses and micro plastic deformations can be reduced on the laboratory scale by the influence of the welding process, and crack formation can be avoided.

Thermal post-processing vacuum electron beam welded seams was carried out by, for example, [23] in order to investigate its influence on the crack growth rate in joined components. Here, it was possible to establish that the tendency for crack growth in the material can be reduced with the aid of post-processing heat treatments using electron beam technology. This is attributed by [23] to the lowering of the residual stresses and the effect of the tempering on the microstructure's martensitic component.

The local increase in the substrate material's hardness by the steel's maraging is described in [24, 25 and 26]. By means of locally heating the welding-seam's region, ageing processes are initiated which lead to modified strength properties.

[27] Describes the improvement of the wear resistance in light-metal materials by increases in hardness. Here owing to its high energy density, energy is introduced by the electron beam for alloying and dispersing.

The assessment of the micro plastic deformations owing to raised local component loading, which is based on the technique of diffracting X-ray beams through the components edge-region as described in $[28,29]$, is not suitable for online applications.

Local work softening of high strength steels by means of locally heat treating using a Nd:YAGLaser and regulating the temperature is introduced in [30]. By means of this softening, higher levels of deformation are to be achieved. Here heat treating takes place locally over a specified section of the component.

The cited examples show very clearly the innovative potential of the new technology by means of which material properties can be locally and specifically calibrated and component damage due to crack formation and growth can be lowered or avoided. Further developmental steps are necessary in order to make future technical use of the enormous potential of this technology in these fields of application.

\section{Manufacturing high quality welded joints}

Designing high quality welded joints with high load bearing capacities for components by using gradient material properties requires the qualification of a welding technology, subject to high static and dynamic loading, for manufacturing defect-free welded-seams. These seams have narrow heat affected zones and their microstructures are aimed at high structural durability [31, 32]. Here, besides a broad spectrum of weldable materials, material composites and sheet thickness, the nonvacuum electron beam welding method in particular provides enormous potential for process control. By means of developing non-destructive, online inspection technologies, a quality assurance is to be realised in the fabrication of high strength components having gradient material properties, Fig. 1. 


\section{Precise positioning of beam head}

1. Problem-oriented eddy-current technology

$\rightarrow$ Influence of edge geometry, material, surfaces

\section{Direct process-monitoring}

2. Evaluation of the process-intrinsic electron and X-rays

$\Rightarrow$ Seam region, welding depth, process response, defect development

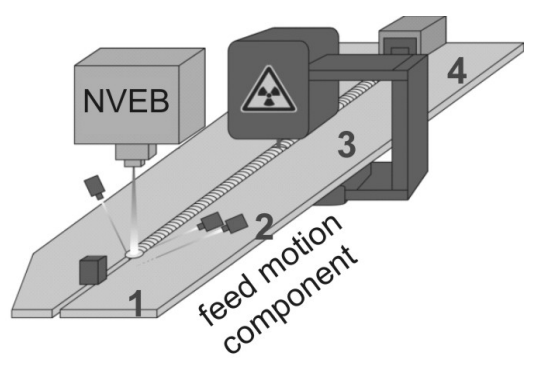

\section{Rapid weld-seam defect inspection in the process-wake}

3. Portable microfocus $X$-ray system with digital image converting technology and high speed camera

4. Development of system for inline remote field eddy-current testing of weld-seam

\section{Realising a process control via}

Online defect inspection Inline process information

Correlation: Process information - test results

Qualification: Testing technology for process control

Fig. 1: Concept for assessing the high quality of NVEB-welded joints

Positioning of the beam to the weld gap. On constructing component joints with high load bearing capacities from high strength materials by using beam technologies, it should be ensured that, besides the construction of a microstructure which is designed for the stress-strain state in the region of the welded-seam, a welded-seam as defect-free as possible is achieved. This requires that the laser or electron beam precisely follows the weld-gap and is always centrally located to this gap in order to avoid beam wandering and, as a consequence, a biased fusion-defect. For this purpose, an online weld-gap tracking system based on an eddy-current inspection system was developed and adapted to the joining process directly in advance of the process region.

Development of eddy-current sensors for weld-gap recognition. The aim of the development work is to realise an eddy-current beam sensor to very precisely determine in advance the weld-gap or the zero-gap position during beam welding. Accordingly, the sensors have to exhibit the following properties:

- high measuring sensitivity vis à vis the weld-gap

- high signal to noise ratio

- Insensitive to spurious variables such as distance effects, edge misalignments and surface coatings

The general principles of the eddy-current inspection are based on measuring the electromagnetic characteristics of a "coil-material" system as a function of the induced alternating magnetic field. The testing configuration is depicted in Fig. 2 using an eddy-current differential sensor in the T-configuration together with a characteristic signal curve above the weld-gap. 


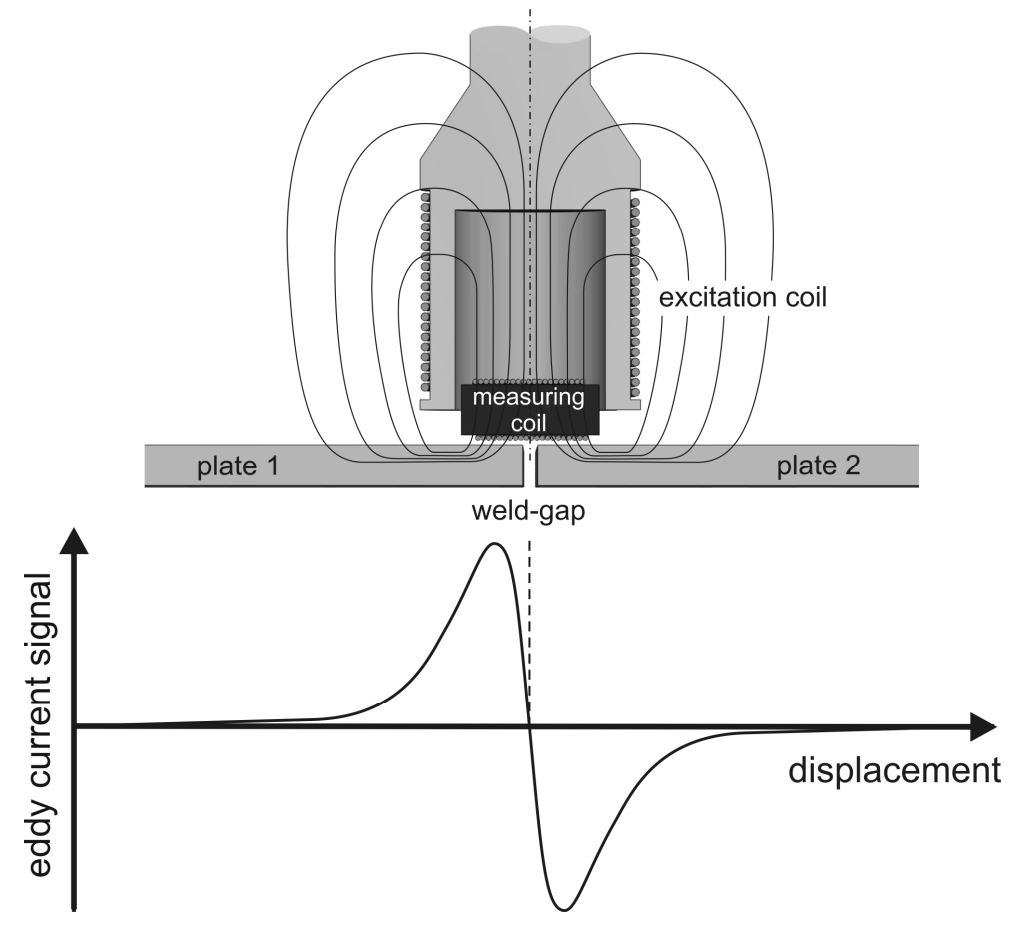

Fig. 2: Eddy-current differential sensor in the T-configuration

Here, the excitation coil, which is arranged perpendicularly to the plate surface, is supplied with an alternating electric current $\mathrm{i}(\mathrm{t})$ which forms the excitation coil's primary field. As a consequence of this and corresponding to the law of induction, an eddy current and/or a flux density distribution results in the electrically conductive and/or ferromagnetic plate material. For this reason, magnetic reversal takes place in the direction of the field lines and the eddy current is formed in the plate as concentric circles opposed to the current flow in the excitation coil. This produces a secondary magnetic field which superposes onto the excited primary field. The measurable change in the magnetic flux $d \phi / d t$ results from the superposition of the primary and secondary fields by means of the windings of the measuring coil, which is arranged perpendicular to the excitation coil. By means of this configuration of the measuring coil to the excitation coil, the measuring coil in the tuned system is calibrated and the measuring signal is compensated. Only through the biased detuning of the coil system by means of the test piece does a field component result in the measuring coil parallel to the plate: this field component provides a measuring signal.

The eddy-current differential sensors in the T-configuration were favoured for this testing task after thoroughly considering different sensor types in preliminary investigations.

These types of eddy-current sensors are, owing to their construction, characterised particularly by their high verification sensitivity to weld-gap or zero-gap at comparatively low sensitivity vis à vis changes in separation distance. This is specifically attributable to the orthogonal configuration of the excitation and the measuring windings. Hereby, a geometric compensation of the primary and secondary fields' normal components is produced. Accordingly, the measuring effect is based decisively on the magnetic field's distortion orthogonal to the gap direction caused by the gap position.

Regarding gap recognition for components having a wall-thickness up to $10 \mathrm{~mm}$, different T-sensors were fabricated, Fig. 3, and the sensor characteristics investigated. 


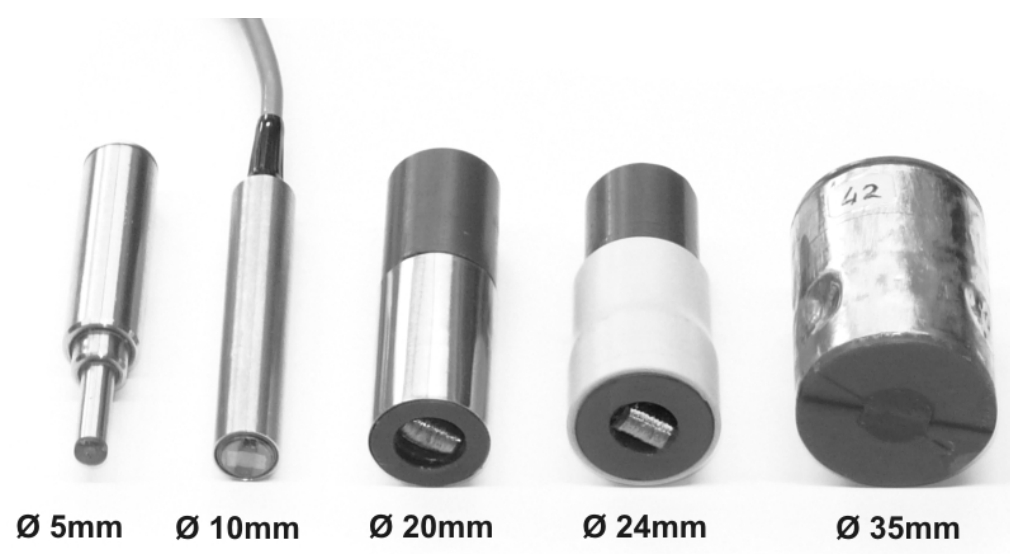

Fig. 3: Developed eddy-current differential T-configuration sensors

An enlarged region of influence of the signal's effective width and amplitude is associated with an increase in the sensor's overall dimensions for similar modulation. Here, the measuring sensitivity, that is the formation of the signal's gradient in the region of the weld-gap, is almost independent of the sensor's overall dimensions, Fig. 4.

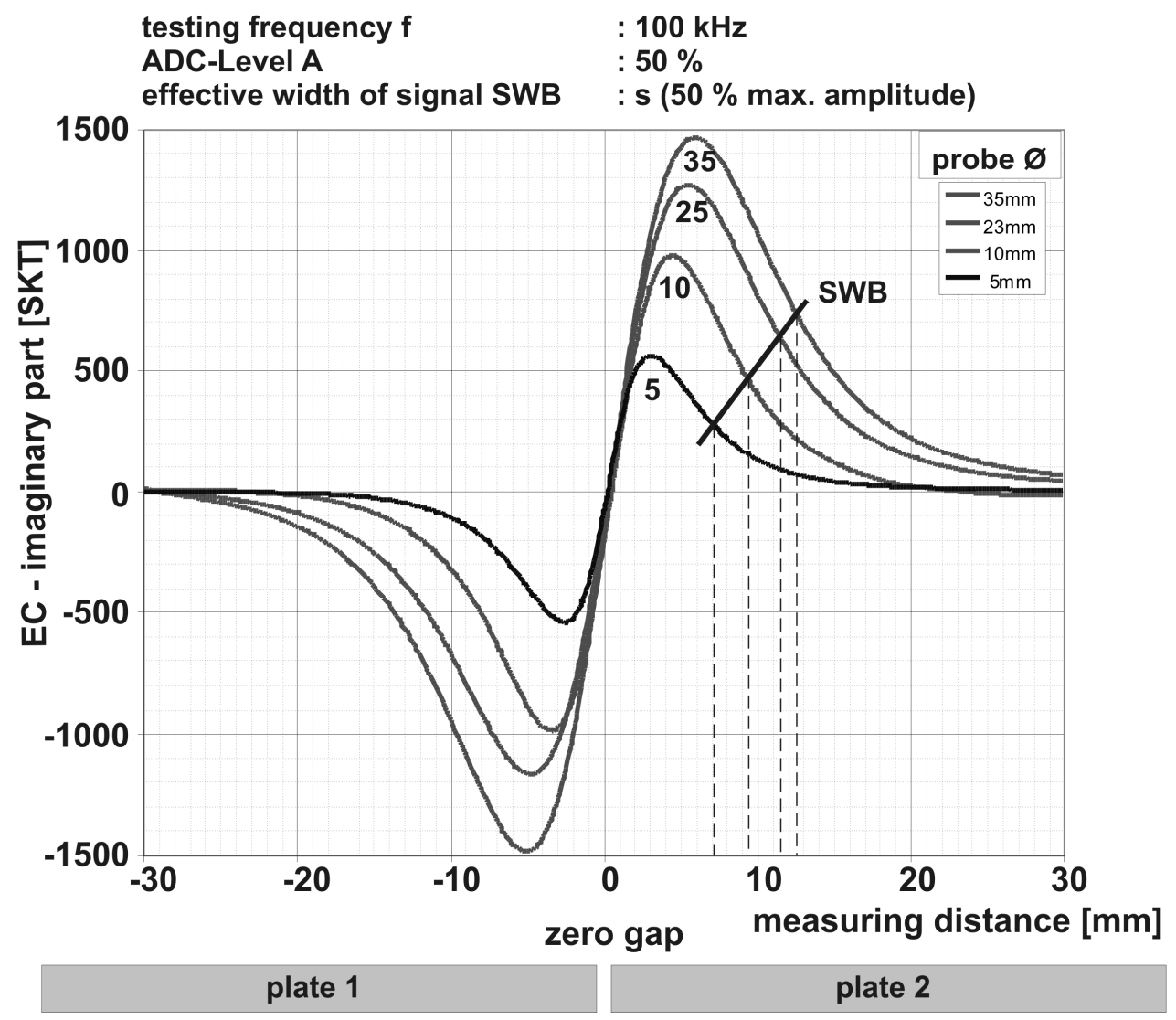

Fig. 4: EC-T-sensor, measuring sensitivity and signal's effective width

Comparatively large sensor separation distances to the welding-gap of up to $6 \mathrm{~mm}$ can be realised with non-contact operating eddy-current T-sensors.

According to the phase separation procedure, the eddy-current technology enables the useful and the spurious signal components to be separate via the variation in the testing frequency, Fig. 5. 


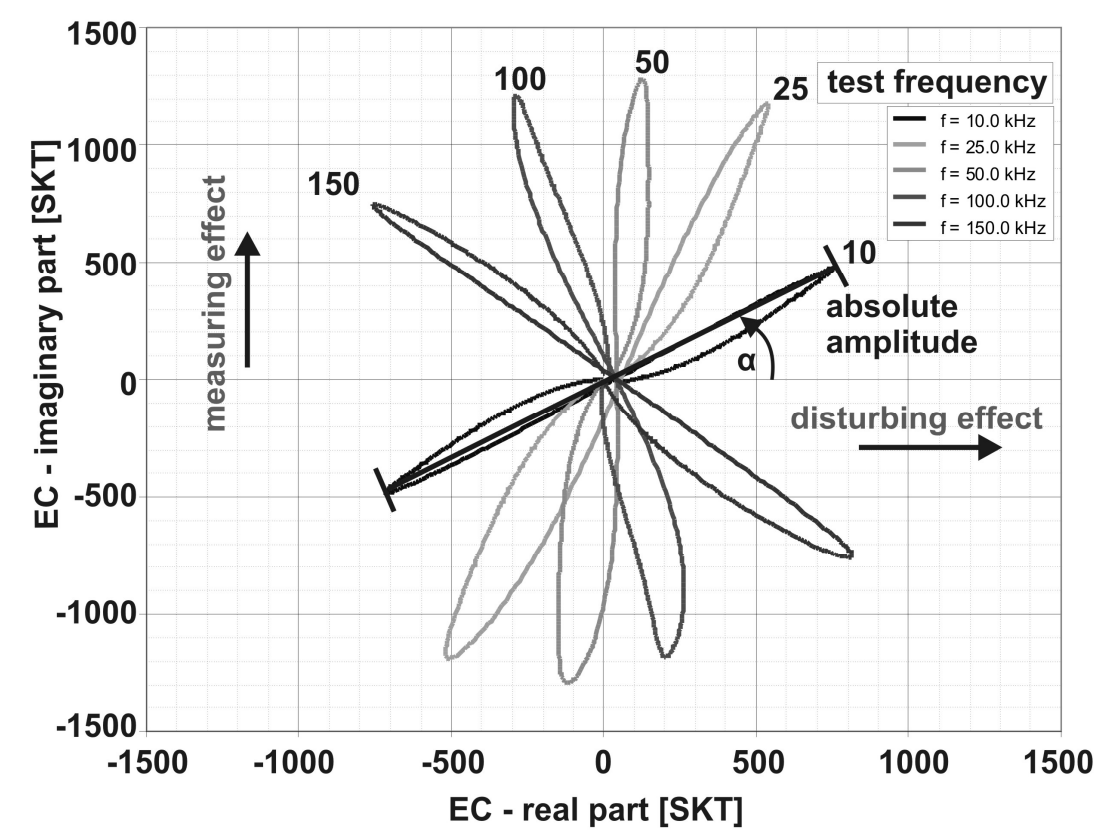

Fig. 5: Separation of the useful and the interference signal components EC-phase separation (impedance level)

The differential signals, detected as measured data, form characteristic double loops which are symmetric about the origin. A continuous rise in the signal phase can be observed with increasing testing frequency for an almost constant development of the signal amplitude. There is an optimum test frequency at approx. $50 \mathrm{kHz}$ for the sensor used. A characteristic feature of this is a signal phase of almost $90^{\circ}$ between the measuring effect in the $\mathrm{Y}$-components and the interference effects in the $\mathrm{X}$-components of the eddy-current signals.

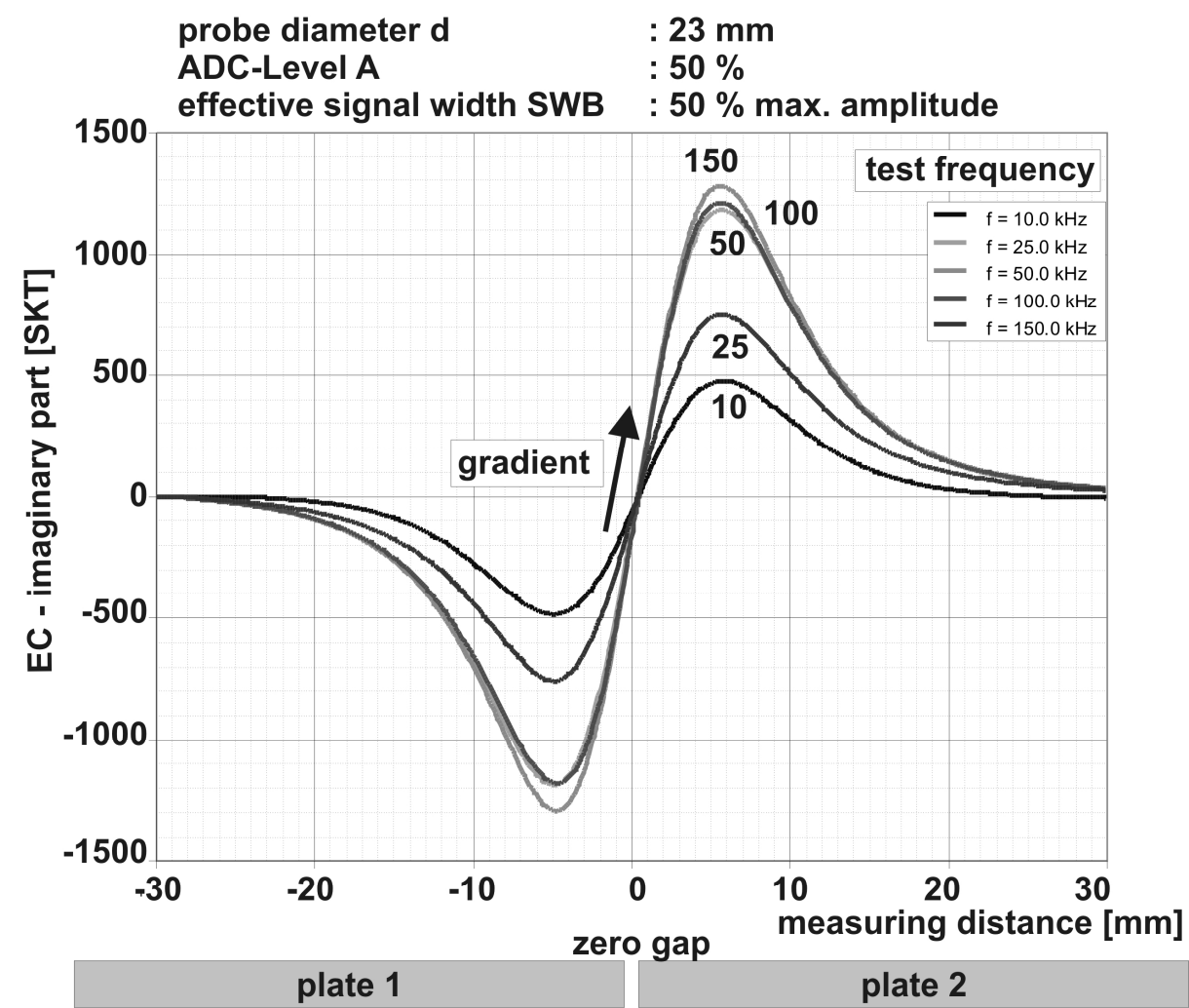

Fig. 6: Influence of the testing frequency on the accuracy of the positioning (Y-signal components) 
For this eddy-current sensor, the useful signal's maximum as well as the steep signal gradient as it passes through the origin, and thereby a high accuracy of the sensor's positioning to the weld-gap, is achieved at a testing frequency of $50 \mathrm{kHz}$ and for a clear separation of the useful and the interference signals, such as distance effects, edge chamfers and misalignments etc., Fig. 6.

Influence of the interference variables on the positioning accuracy. On observing the behaviour of the eddy-current sensor's signal, it is clear that the signal amplitude decreases with increasing sensor distance which accompanies a drop in the signal gradients, Fig. 7.

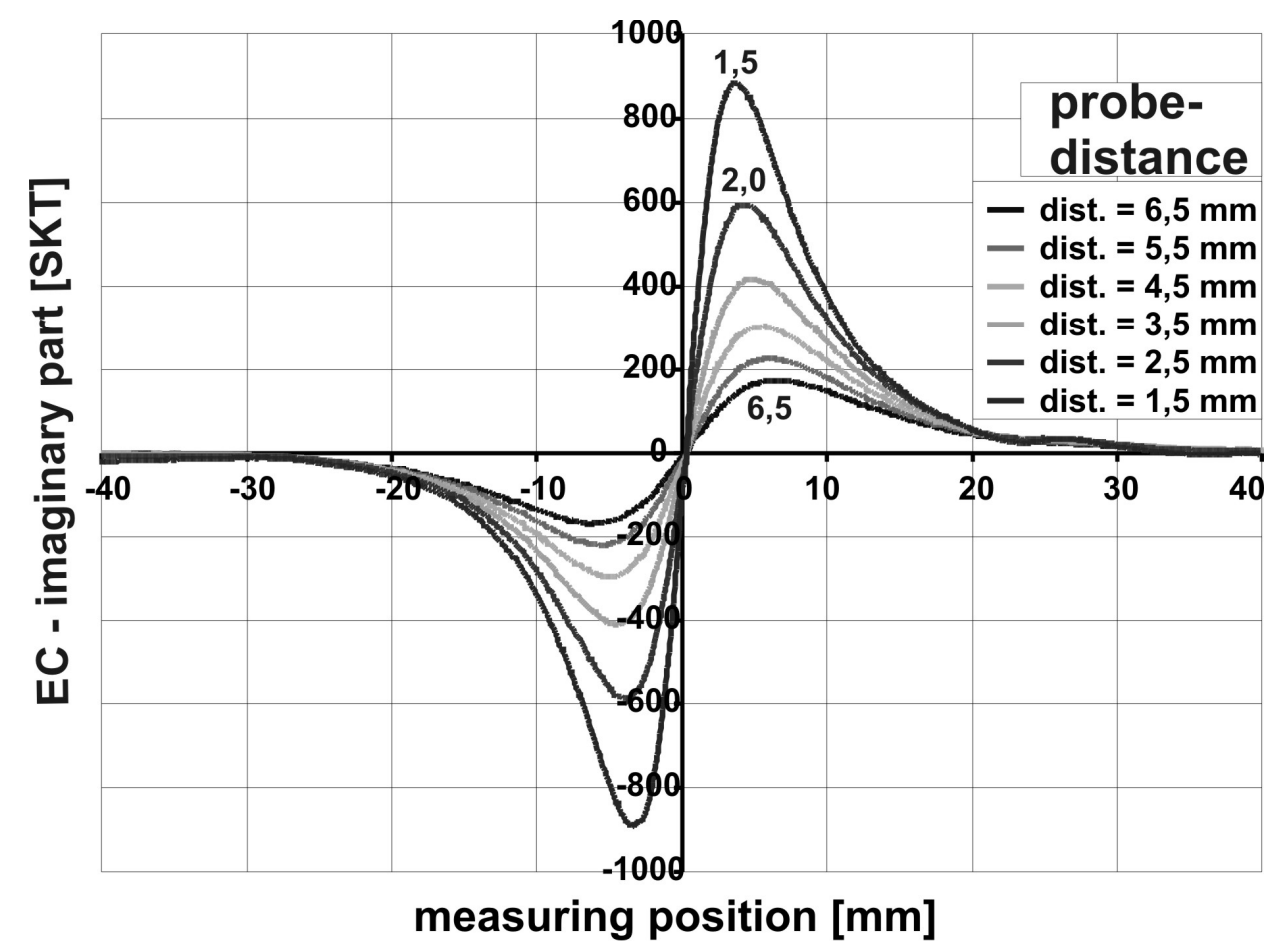

Fig. 7: Variation the sensor's distance to the component's surface

However, this has only a slight influence on accuracy of the positioning.

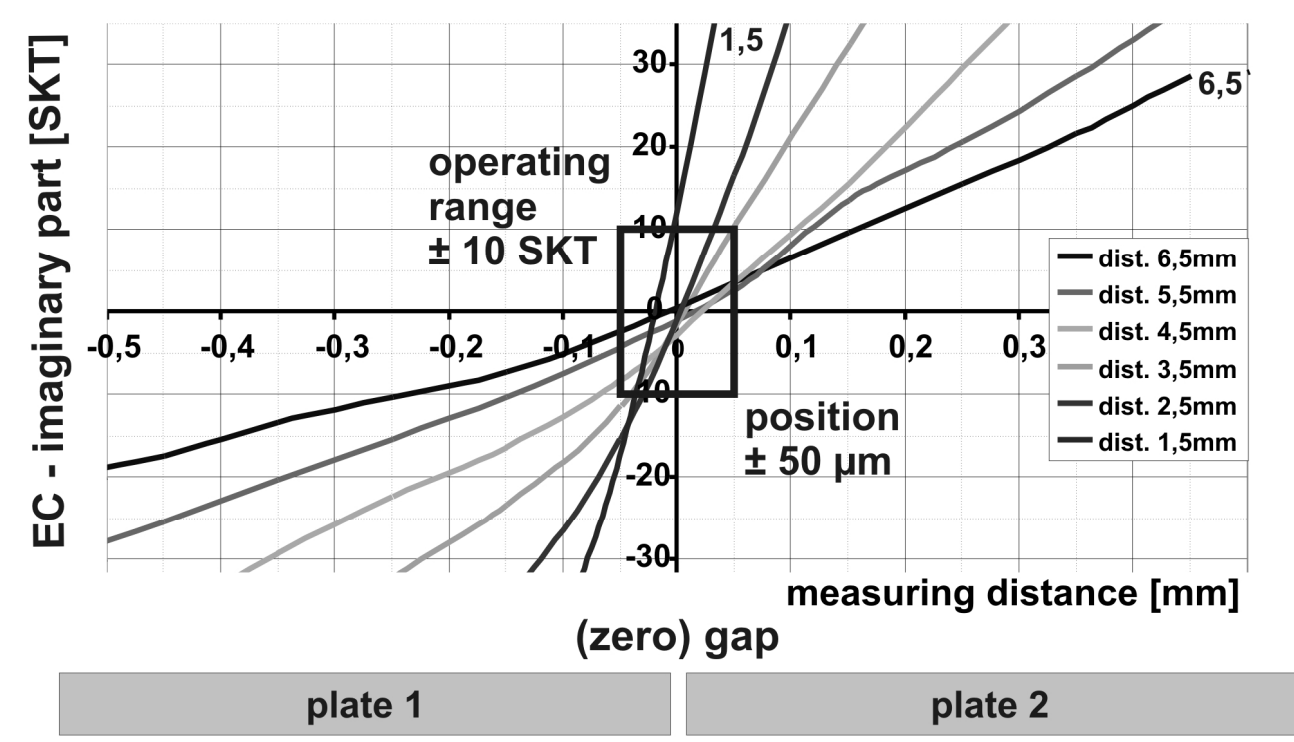

Fig. 8: Influence of the sensor's distance on the positioning accuracy 
For a specified deviation of the eddy-current signal from the zero position of \pm 10 SkT (threshold value), a positioning accuracy of $\pm 50 \mu \mathrm{m}$ is achieved for an average sensor/component distance of $2.5 \mathrm{~mm}$ and a distance tolerance of $\pm 1 \mathrm{~mm}$ for an operating range of $1.5 \mathrm{~mm}$ to $3.5 \mathrm{~mm}$, Fig. 8 .

An edge misalignment between the weld-pair has a significant influence on both the formation of the eddy-current signal curve above the gap as well as the eddy-current loops at the impedance level, Fig. 9.

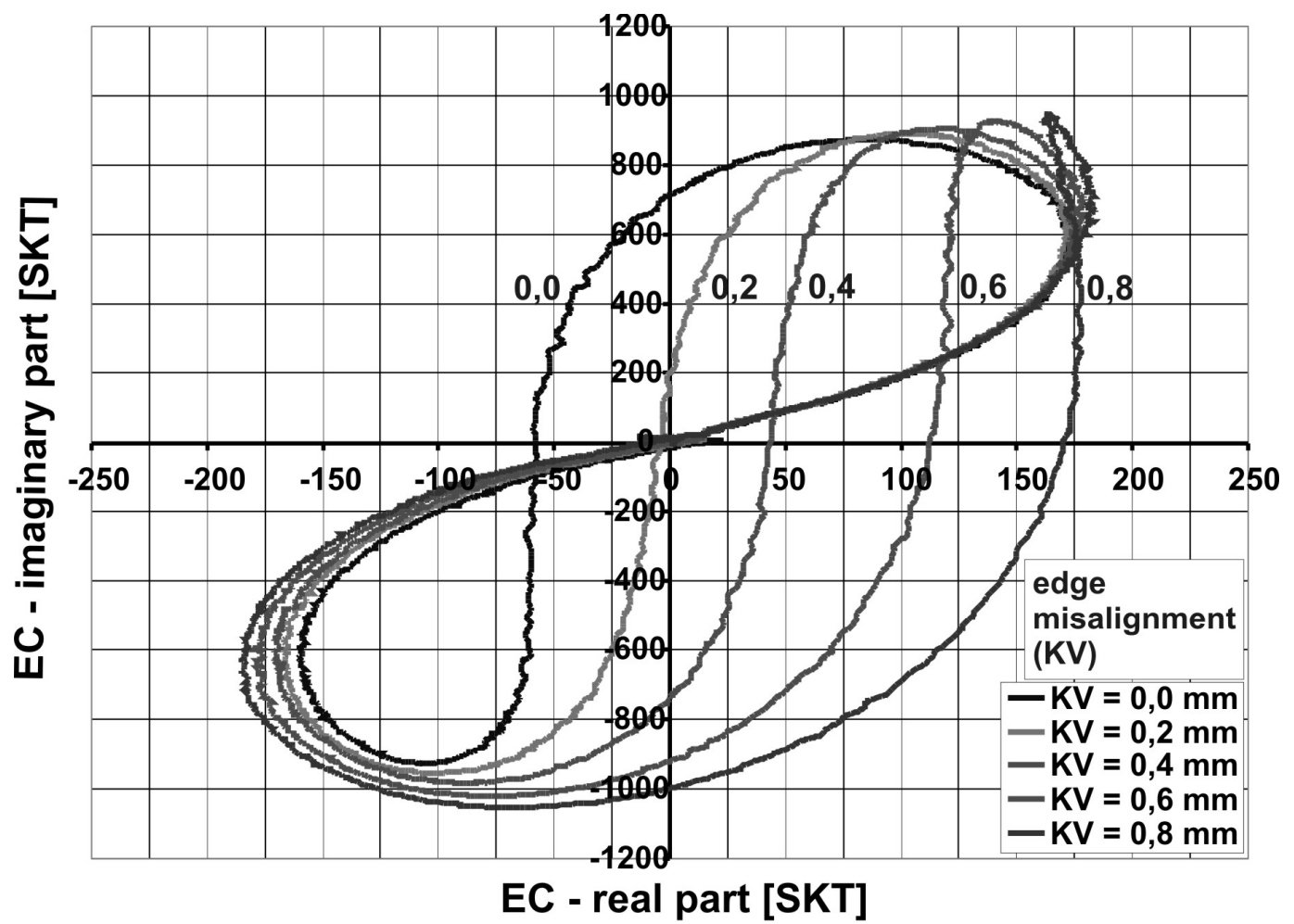

Fig. 9: Influence of the edge misalignment on the eddy-current loops at the impedance level

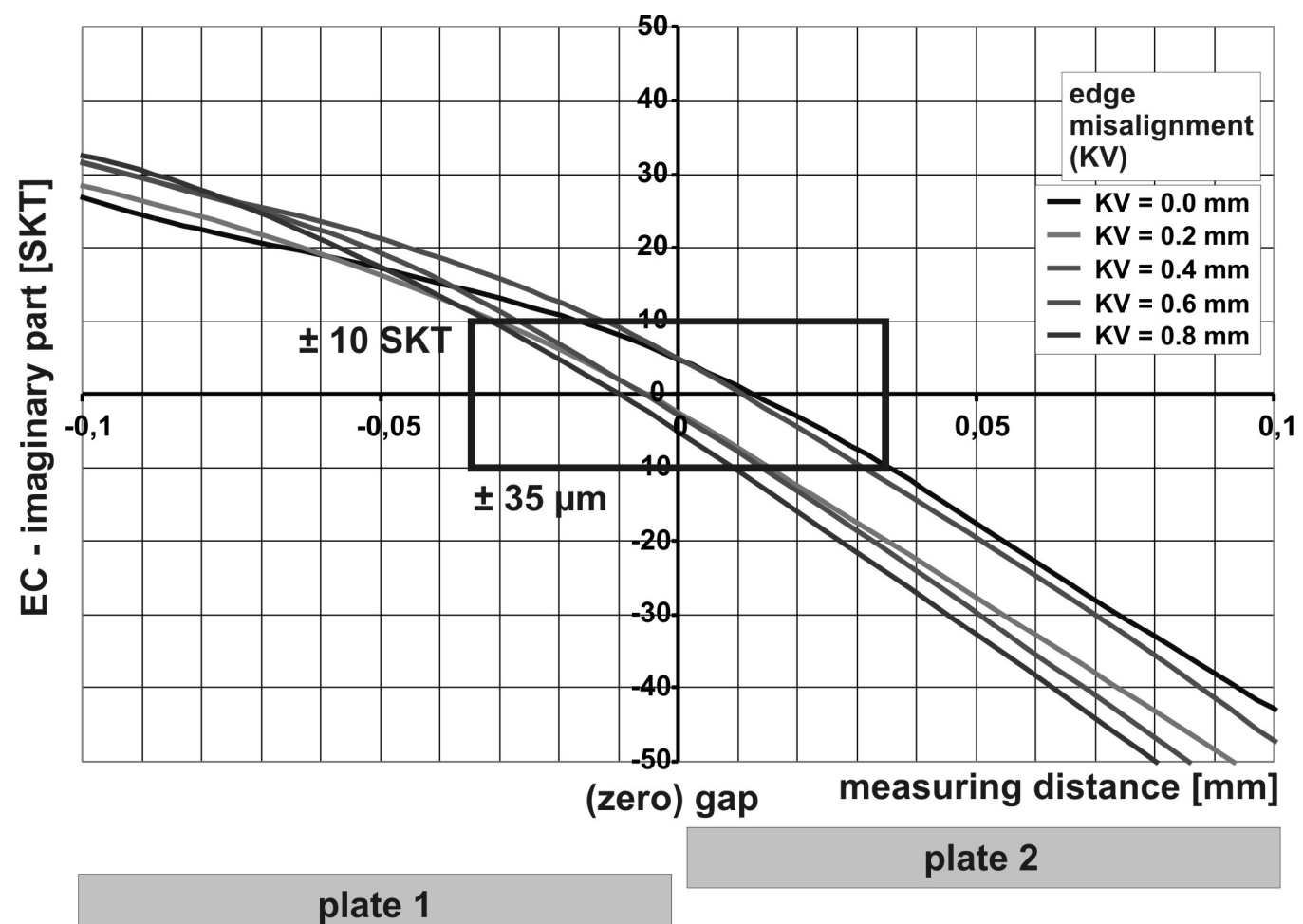

Fig. 10: Influence of the edge misalignment on the accuracy of the positioning 
However, as a consequence of compensating for the interference variables for the eddy-current $\mathrm{T}$ sensor, an edge misalignment or chamfer is similar to a change in distance and only affects the signal's interference component, which is contained in the eddy-current's X-component, and not in its useful Y-component signal.

By both developing a special eddy-current differential sensor in a T-configuration as well as separating the useful and interference signals, an eddy-current sensor technology having a height positioning accuracy of better than $\pm 35 \mu \mathrm{m}$ has been successfully realised by optimising the testing parameters, Fig. 10.

EC-T-sensor testing system for gap detection and beam tracking. A computer based EC-Tsensor testing system has been conceived and developed to implement weld-gap recognition in front of the weld-pool and to position the electron beam at the joint gap, Fig. 11.

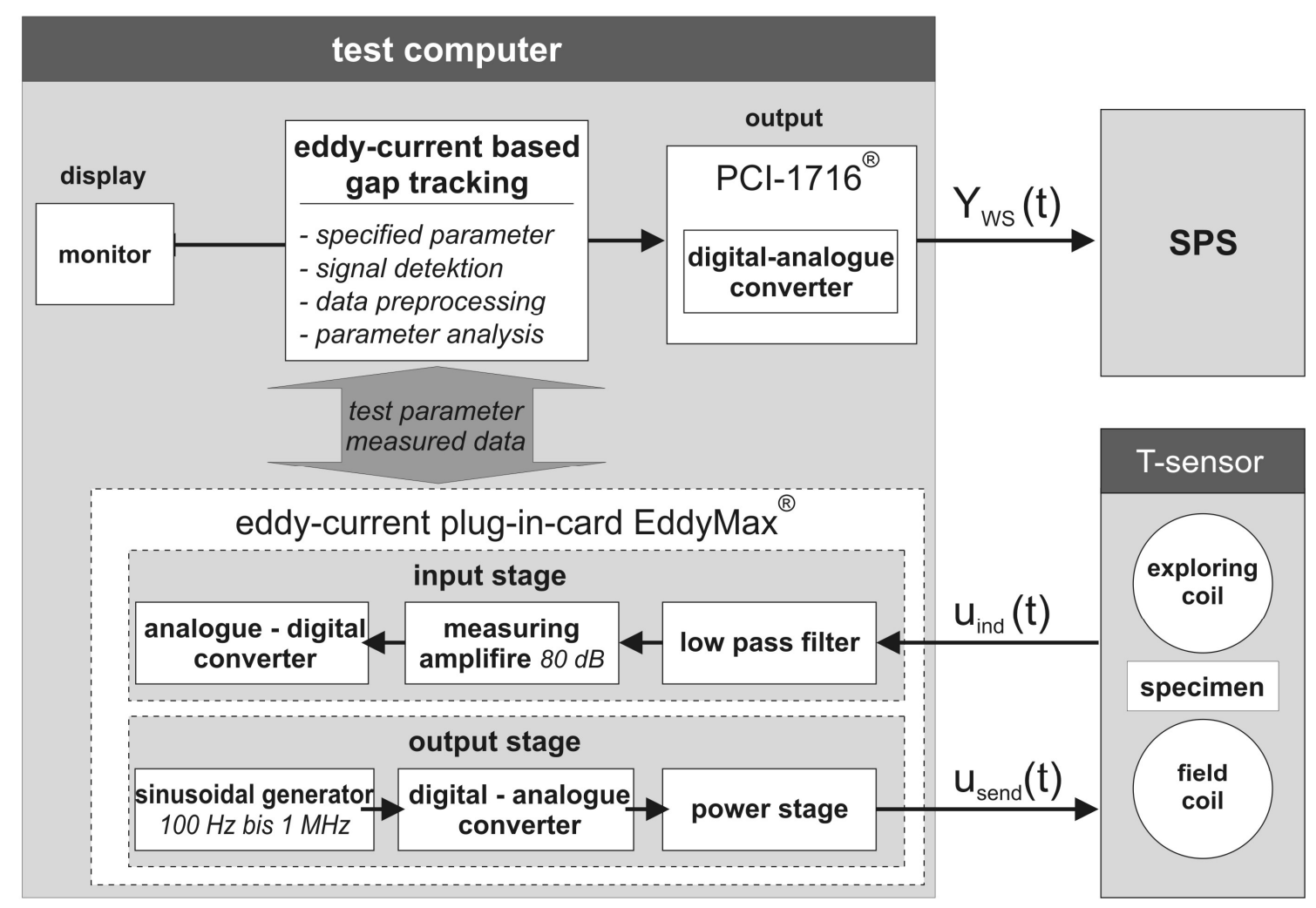

Fig. 11: EC-T-sensor testing system for gap tracking and beam control

The testing system consists of the following hardware components:

- Portable data processing computer

- Eddy-current plug-in board EddyMax ${ }^{\circledR}$

- PCI-1716 digital-analog converter

- EC-T-testing sensor

- EC-T-sensor linear axis

The testing software ECGT "eddy-current based gap tracking", which is installed on the data processing computer, controls the hardware system components and enables the testing and controlling sequences to be automated. Gap detection by means of the EC-T-sensor takes place via the eddy-current plug-in card where the sensor's signal is used at a testing frequency of $f_{p}=20 \ldots 200 \mathrm{kHz}$ together with a cycle rate of $2 \mathrm{kHz}$ as a digital control signal for rapid sensor and beam positioning.

The use of an eddy-current T-sensor on a linear axis in front of the weld-pool for automated gapdetection and beam positioning is depicted in Fig. 12. 
- weld-gap detection using EC-T-sensor

- sensor positioning to the weld-gap

- independent beam positioning in the wake of the sensor

beam positioning in the wake of the T-sensor

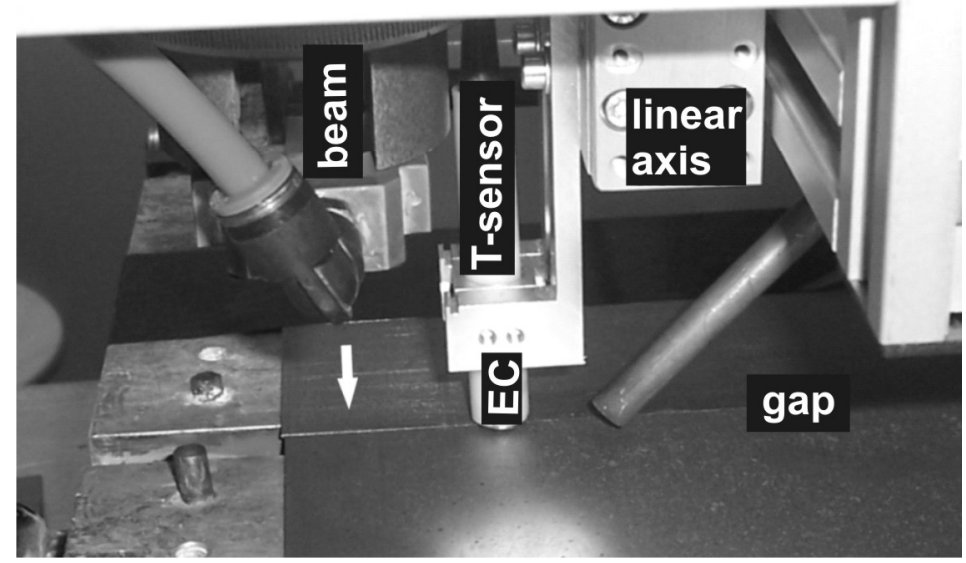

Fig. 12: Automated gap detection and beam control using a EC-T-sensor

Process monitoring of the weld-pool during NVEB welding. Besides the material and the atmosphere, the grade and quality of a welded joint essentially results from the welding process. Here, the formation of the weld-pool together with the energy input is particularly important with regard to the formation of the microstructure, zero-defect tolerance and the material condition adjacent to the weld-seam and the heat affected zone. With respect to the transformation of energy, the reflected electron-scattering and the X-rays supply significant information about the formation of the weld-pool, the weld-pool dynamics and the weld penetration depth [34] and thereby provides the possibility for online process monitoring, process control and quality assurance during nonvacuum electron beam (NVEB) welding.

Configuration of a beam measuring system for NVEB weld-pool monitoring. With the objective of assessing the quality during non-vacuum electron beam welding, an electron and X-ray measuring system is constructed in the form of a process module for online weld-pool monitoring, Fig. 13.

The detecting system is configured to detect the process-intrinsic electron scatter-beam reflections and roentgenbremsstrahlung. 1" NaI:TI-detectors (sodium iodide: thallium doped) were employed to detect the X-rays and a 1"YAP:Ce-foil detector (yttrium aluminium perovskite: cerium doped) having a high sensitivity to electrons. The radiation detectors are located in a collimatorscreening housing and are configured in a detector-recorder around the electron beam in a star shape. In the detector-recorder, up to 8 detectors can be held and finely positioned in the direction of the weld-pool.

To shield from the surrounding spurious-radiation, the radiation detectors are secured in a hermetically sealed collimator-shielding housing of lead bronze $\mathrm{CuPb} 15 \mathrm{Sn} 7$ together with additional lead screening, Fig. 14. 


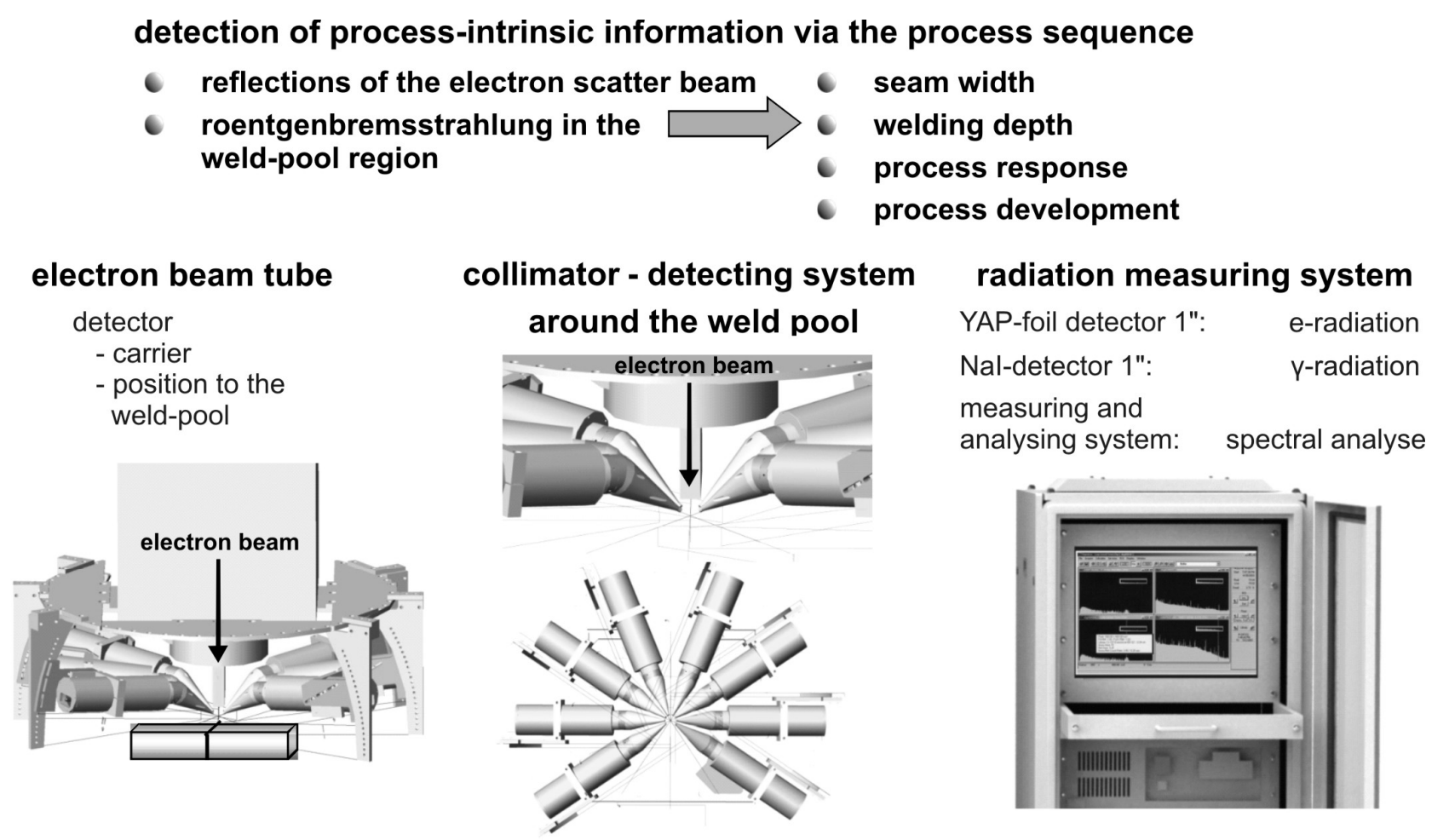

Fig. 13: Weld-pool monitoring and analysis during electron beam welding

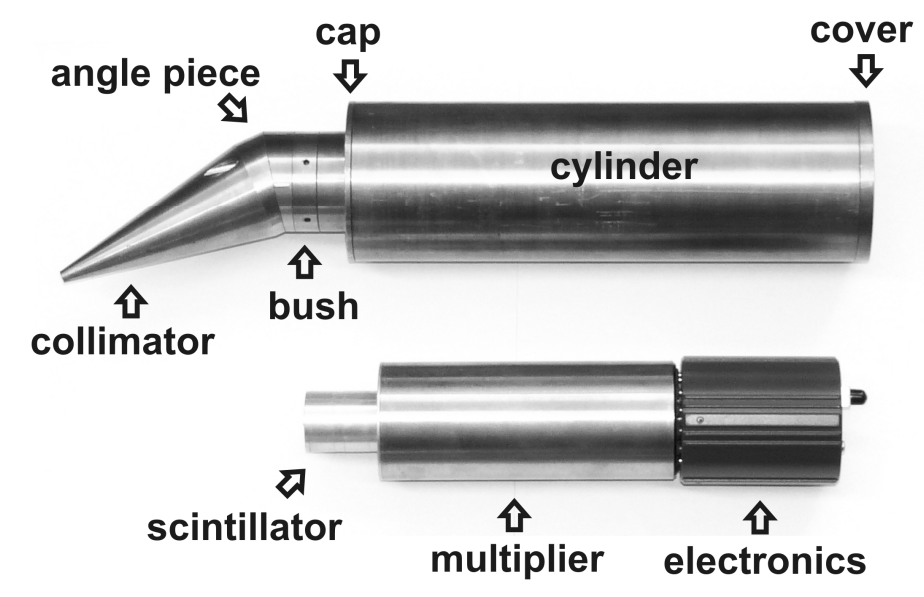

Fig. 14: NaI- or YAP-radiation detector with collimator-screening housing

The detector's measuring electronics are also located together with the detector in the screening housing. Here, the detector's supply and data-transfer takes place by means of a 16 channel radiation-measuring system, Fig. 13, via a digital USB connector.

A local and differential examination of the energy transformation in the weld-pool requires that the radiation source be well shielded by a very fine collimator in front of the detecting system. However, the electron-beam equipment's very high beam power, of up to $25 \mathrm{~kW}$, as well as the welding-pool's energy densities and radiation dose-rate, it is required that the detector's input radiation be restricted in order not to overburden the detector-verification system with respect to the counting rate. In this regard, the detector-collimator port was initially reduced from $1 \mathrm{~mm}$ to $0.2 \mathrm{~mm}$ diameter by combining several $20 \mathrm{~mm}$ long tube sections and then to two circular segmental ports having a slit width of $45 \mu \mathrm{m}$, using an addition copper-core, Fig. 15. 


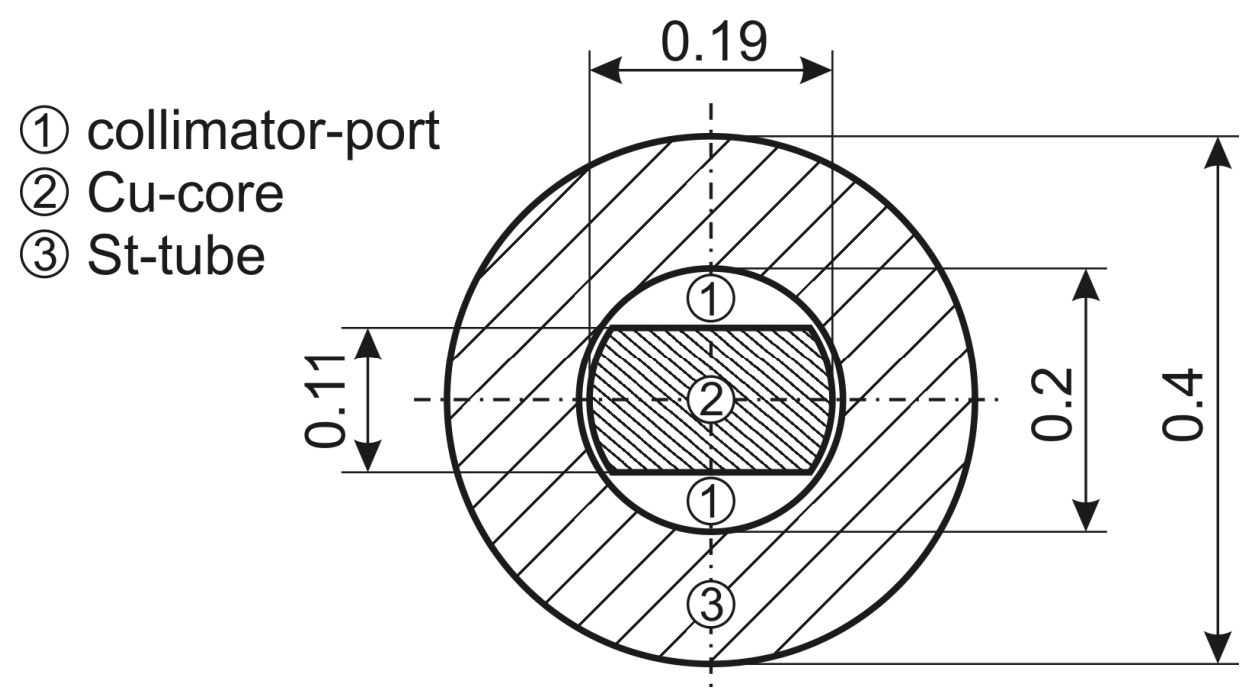

Fig. 15: Circular segment slit-collimator

Calibration of the detector-energy spectrum. An energy-specific examination of the roentgenbremsstrahlung requires that the detector-spectrum port be calibrated. For this purpose, radioactive sources are employed which have known and discrete energy lines in the relevant energy range. To calibrate the radiation-detectors within the energy range of the electron beam tube, which has a maximum energy of $175 \mathrm{keV}$, an AM-241 radiation source was used which has its main gamma line at $59.5 \mathrm{keV}$.

Fig. 16 depicts the recorded energy spectra of NaI- and YAP-detectors within the radiation field of an AM-241 source. As a consequence of their different sensitivities, the spectra of both detectors show the formation of material specific and discrete energy lines at different intensities.
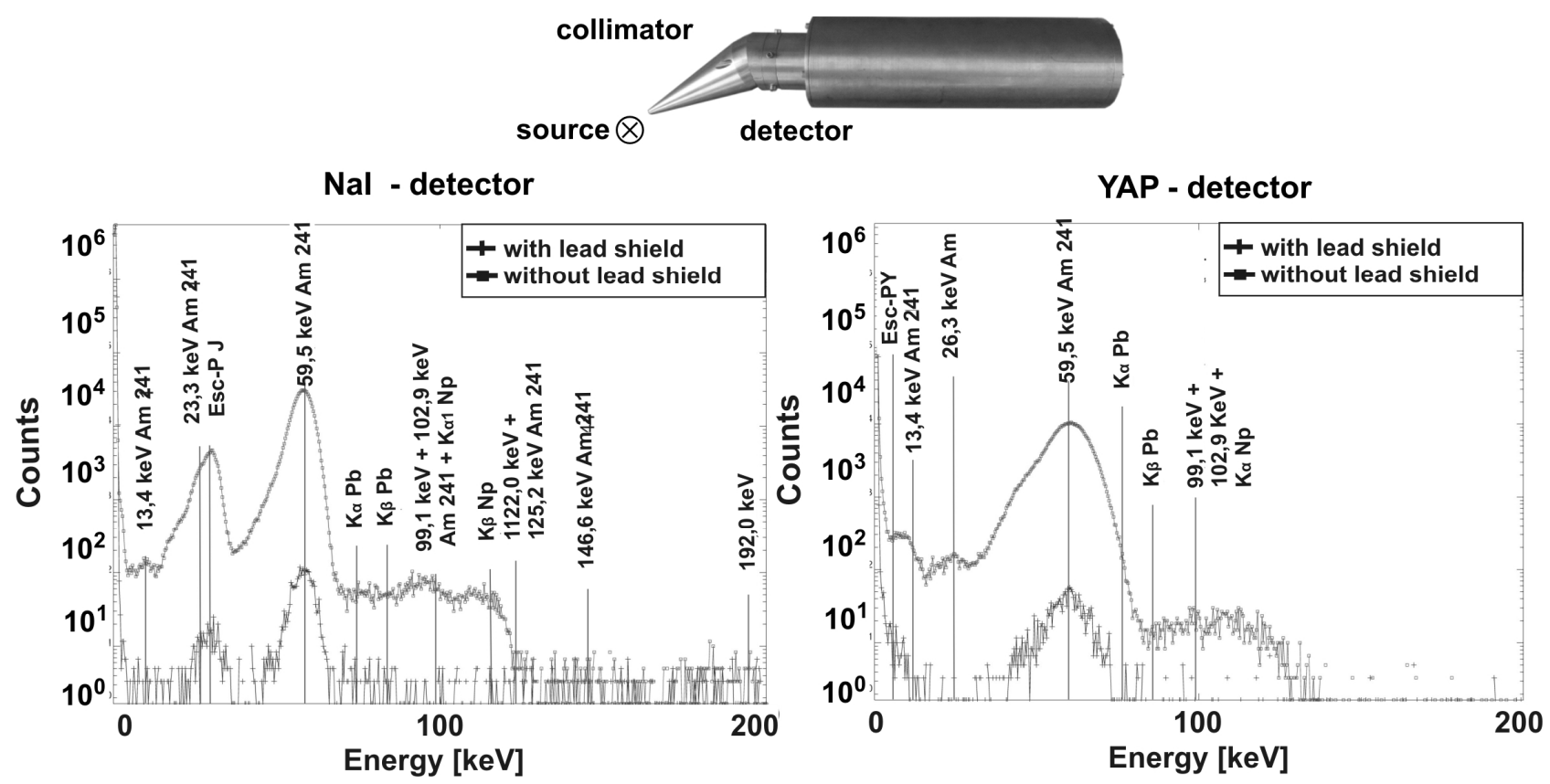

Fig. 16: Energy spectra to calibrate the NaI- and YAP-detectors

NVEB weld-pool monitoring using radiation detectors. An in-line test of the NaI- and YAP radiation-detectors for monitoring the weld-pool was carried out on the non-vacuum electron beam equipment at the Institute of Materials Science ("Institut für Werkstoffkunde - (IW)") of the Leibniz University Hanover (LUH). The NVEB equipment operates with an acceleration voltage of $175 \mathrm{keV}$ and an electron current of $1 \ldots 140 \mathrm{~mA}$ corresponding to the maximum beam power of $25 \mathrm{~kW}$, Fig. 17. 


\section{NVEB electron beam equipment PTR NV-EBW 25-175}

accelarating-voltage

$\mathrm{U}=175 \mathrm{kV}$

electron current

$\mathrm{i}_{\mathrm{e}}=140 \mathrm{~mA}$

beam-power

$P_{\mathrm{St}}=25 \mathrm{~kW}$

operating distance

a $=10 \ldots 50 \mathrm{~mm}$

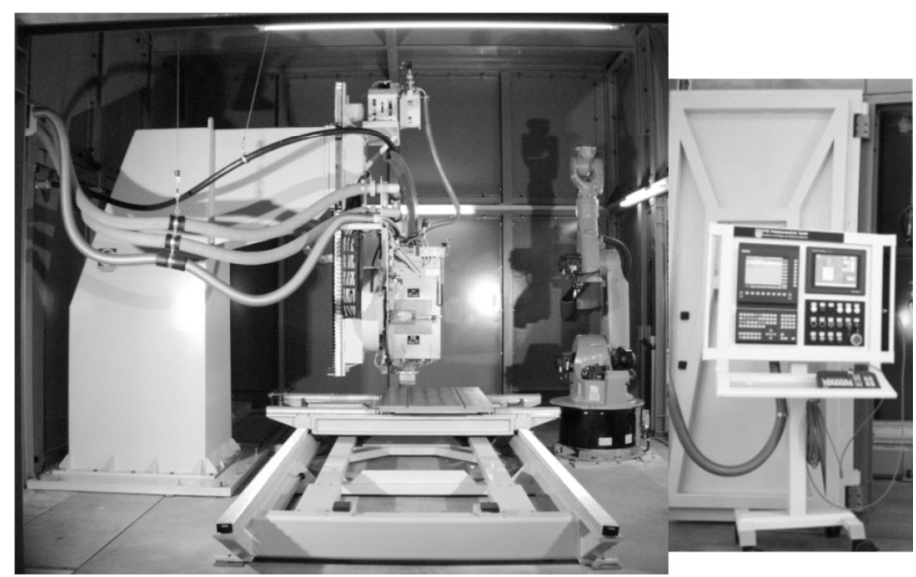

Fig. 17: Non-vacuum electron beam welding equipment

The electron beam emerges from the vacuum in the electron beam gun into the atmosphere via a three stage helium-cascade. According to the processing specifications, the operating distance can be adjusted from 10 to $50 \mathrm{~mm}$. The widening of the emerging electron beam into the atmosphere is shown in a)

b)

Fig. 18a by means of the light spectrum produced by the collision of the electrons with the atoms of helium and air.
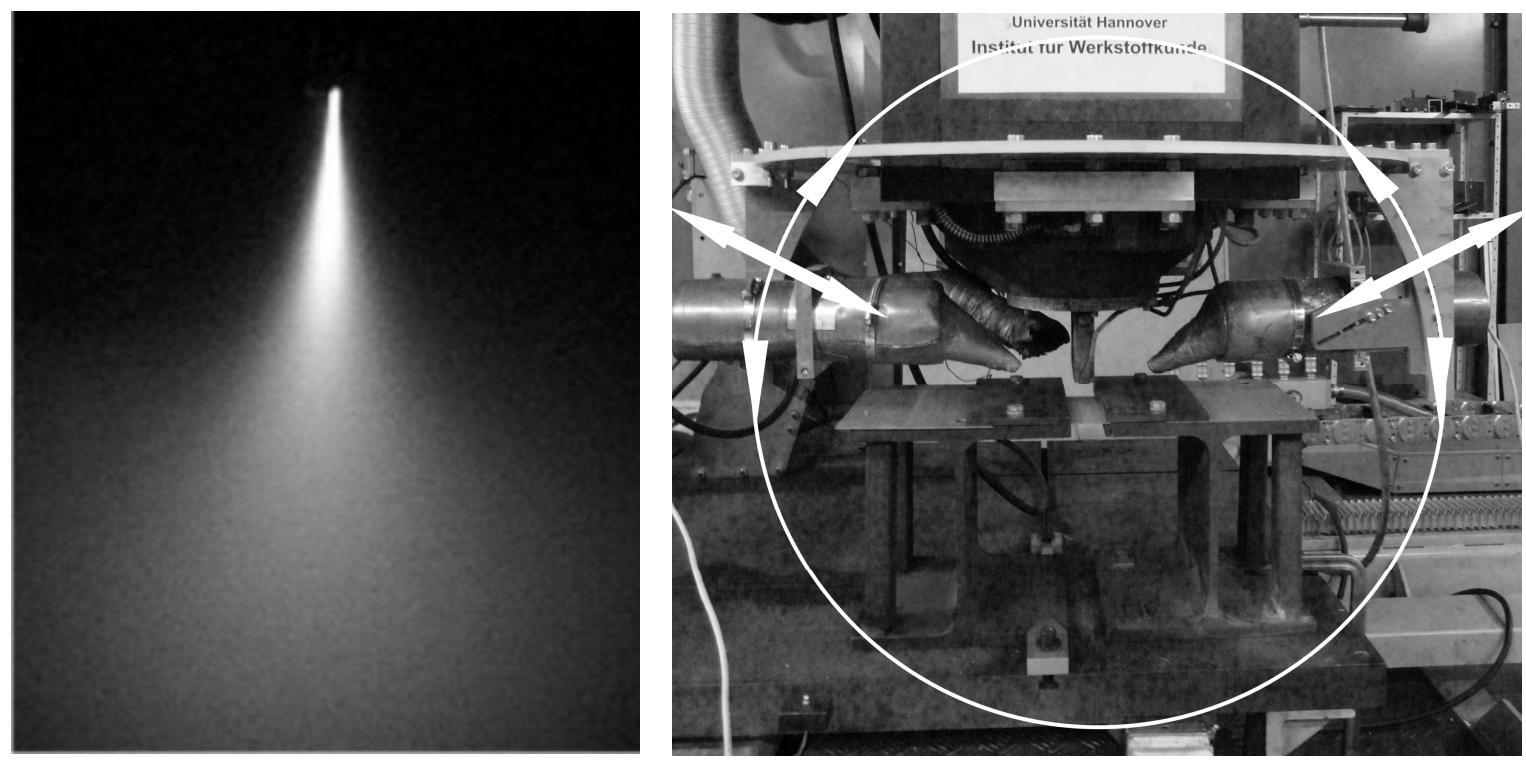

a)

b)

Fig. 18a: Light spectrum and widening of the electron beam

Fig. 18b: Radiation detectors with additional lead screening and the collimator's alignment to the weld-pool 
Owing to the high X-ray dose rate in the electron beam's radiation field, the radiation detectors are screened with an additional surrounding $9 \mathrm{~mm}$ thick lead screen vis à vis the background radiation. The radiation detectors are clamped to the head of the electron beam's gun beneath the nozzle in a detector-retainer. The detector's retainer enables individual and flexible alignment of the separate detectors regarding their setting angle, their collimator distance as well as their local collimator alignment to the weld-pool region, a)

Fig. 18b.

Initial investigations to test the radiation-detector's measuring system subject to the relevant process conditions was carried out during the electron beam welding of thin sheets and by artificially introducing irregularities into the weld-joint region. In the first place, these irregularities consisted of changes in the weld-joint's geometry as well as in the keyhole formation and secondly, the influence of foreign materials and alloying elements on the energy transformation and the radiation spectrum.

Online, roentgenbremsstrahlung measurements of the weld-pool taken during the electron beam welding of fine sheets, which had small defects introduced into the weld-gap, show both a high verification sensitivity to the counting rate and the pulse spectrum as well as a pulse response to irregularities in the process sequence, Fig. 19.

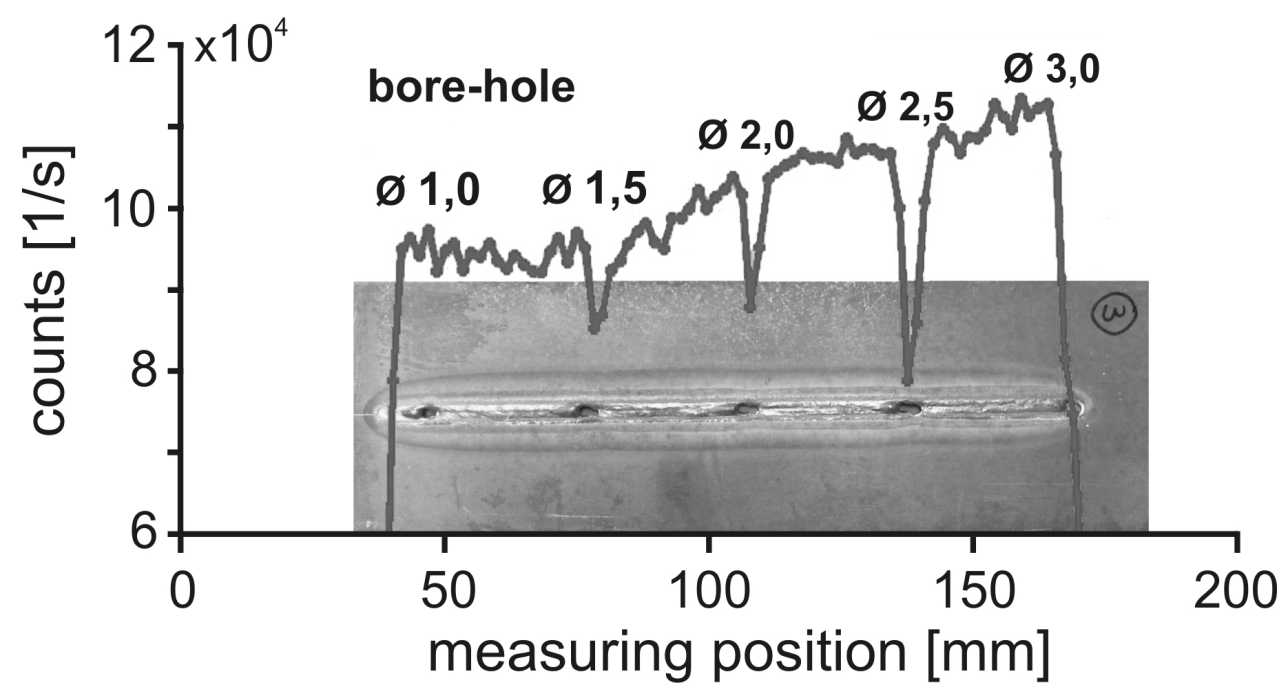

Fig. 19a: Radiation detection of irregularities in the weld-gap - boreholes in the gap

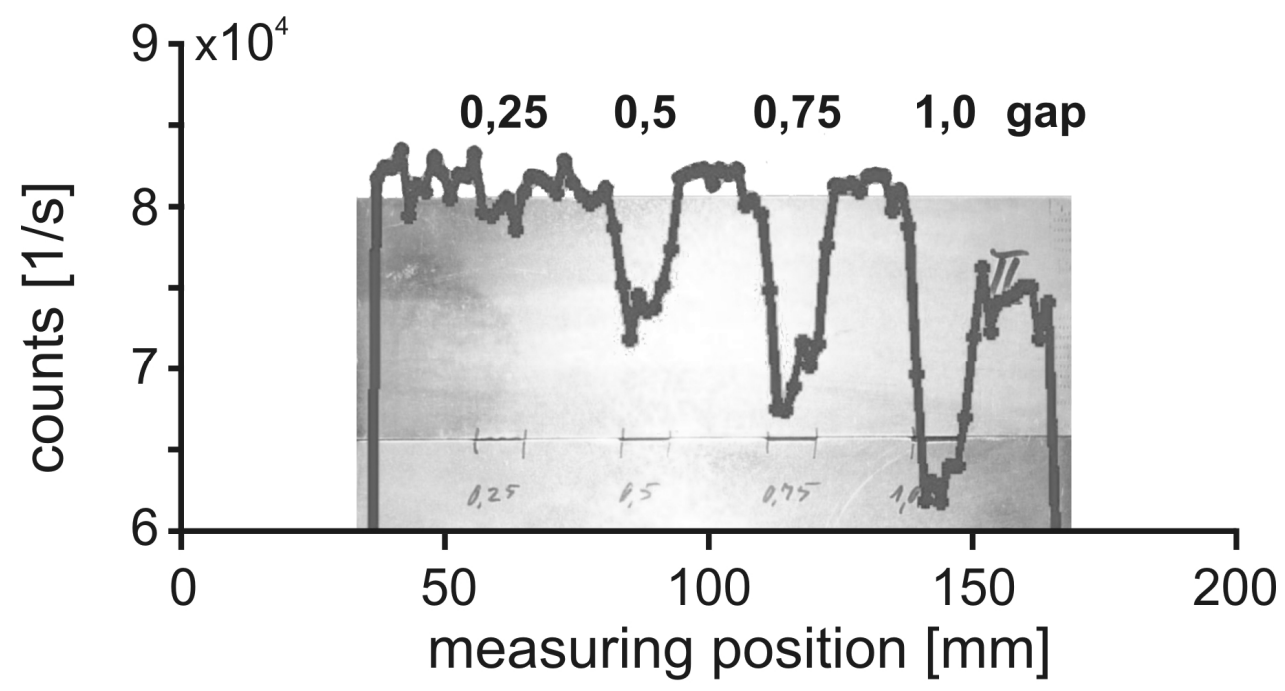

Fig. 19b: Radiation detection of irregularities in the weld-gap - local gap widening 


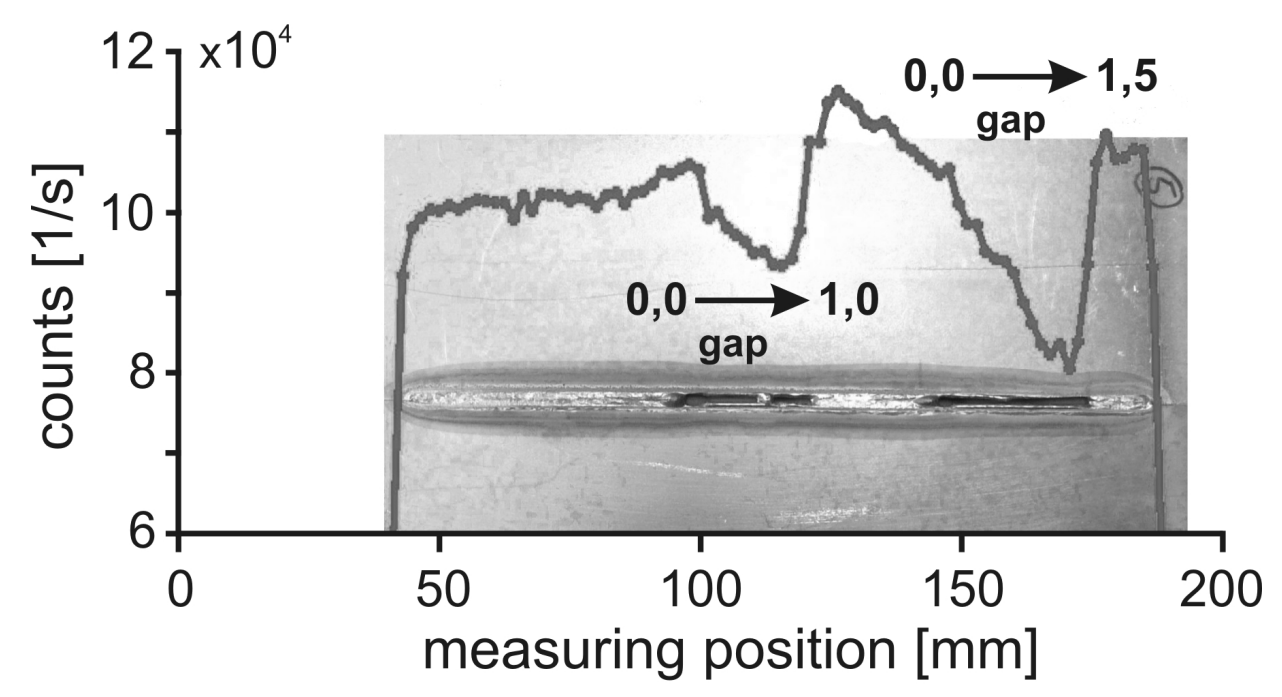

Fig. 19c: Radiation detection of irregularities in the weld-gap - conically widened gaps

By means of the high counting rate's response, the cut in and out of the electron beam's circuit is detected online and thereby the start and finish of the welding process in the component. However, deviations in the beam power also lead to changes in the energy transformation in the weld-pool and can be tracked by the response rate as a development trend of the process sequence, Fig. 19.

Changes introduced into the weld-gap's geometry, such as drilled holes from 1.0 to $3.0 \mathrm{~mm}$ diameter, see Fig. 19a, and local gap widening from 0.25 to $1.0 \mathrm{~mm}$, see Fig. 19b, as well as conically widened gaps from 0.0 up to $1.0 \mathrm{~mm}$ and 0.0 up to $1.5 \mathrm{~mm}$, see Fig. 19c, are material deficiencies in the weld-gap. These local reductions in the volumetric interaction with the electron beam almost accompany the energy transformation in the weld-pool and are manifested as significant interruptions of the X-ray count rate detected as measured data. Here, the change in the count rate is approximately proportional to the gap width and to the reduced effective volume. For large gap-widths and insufficient gap-bridging, weld-seam defects occur in these regions.

Effect of material and composition in the weld-gap. On electron beam welding alloys or dissimilar parent materials, the materials and alloying elements involved are particularly important. Here, the interaction of the electrons increases significantly with the atomic mass of the elements culminating in the heavy elements such as copper, tungsten and lead. In order to investigate the influence of foreign materials or alloying elements on the energy transformation in the weld-pool, thin foil sections of copper, tungsten and lead were locally embedded in the weld-gap and welded to its mating part. The count rate for a NaI:TI detector and a YAP:Ce detector during overlay-welding of $\mathrm{Cu}$-foils each with three sections is depicted in Fig. 20.

As described above, on overlay-welding of $\mathrm{Cu}$-foil sections, a larger energy transformation occurs in the weld-pool which manifests as an increased X-ray count rate. This type of effect was confirmed on introducing tungsten and lead foil sections into the weld-pool. The influence of alloying and foreign elements in the weld-gap can be particularly clearly verified in an increase of the elements own characteristic X-ray lines recorded in the X-ray spectrum. 

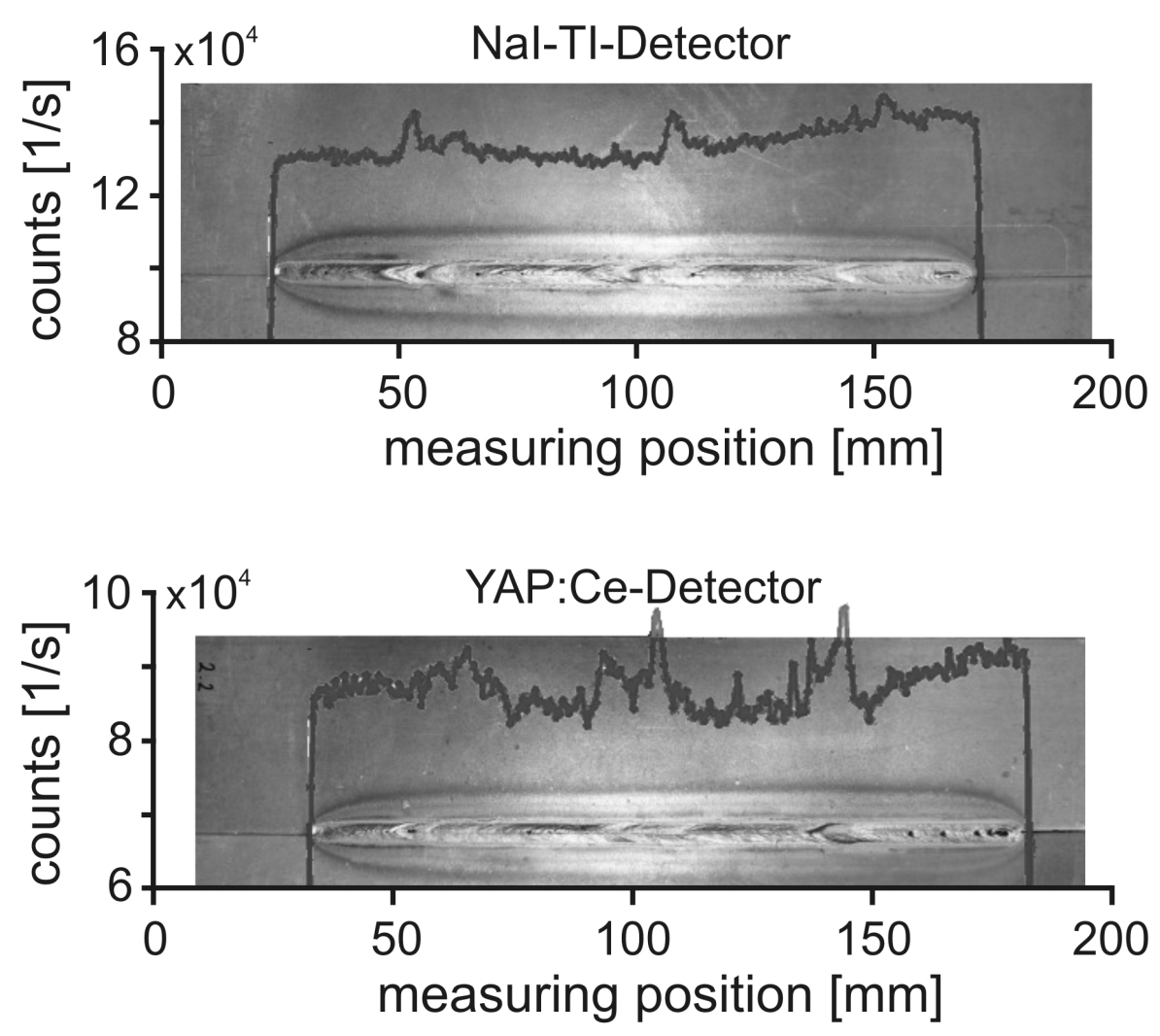

Fig. 20: Influence of foreign elements on the energy transformation

Monitoring the NVEB deep welding processes. Beam technology, such as non vacuum electron beam welding with a high beam power and a good overall efficiency of $\sim 40 \%$ to $50 \%$, the deep welding process enables single-pass joining of both thick-walled and high strength materials. Here, an essential influence on the formation and quality of welded-seams is the welding depth via the required keyhole formation and the process stability. For this reason, monitoring the deepwelding process during single-pass joining of thick-walled components is vitally important within the framework of a quality assurance system.

In order to investigate the suitability of the radiation-measuring system for monitoring deepwelding processes, initial measurements were carried out during electron beam welding of test specimens having blind-holes. In one test specimen with a wall-thickness of $4 \mathrm{~mm}$, three blind-holes each having a diameter of $3 \mathrm{~mm}$ were drilled to depths of 1,2 and $3 \mathrm{~mm}$. To monitor the welding process, roentgenbremsstrahlung was detected as measured data in the weld-pool by using a collimated NaI:TI-, as well as YAP:Ce detector which was focused on the weld-pool from the upper- and undersides. The positioning of the specimen beneath the electron beam's tube and aligned to the detector from the underside to the weld-pool is depicted in Fig. 21. During overlaywelding of the blind-holes in the test specimen using the electron beam, the region of energy transformation is shifted to greater depths with increasing hole-depth. This leads to a rise in the count rate on the underside and to an analogous drop on the specimen's upper side by virtue of the modified radiation screening in the component on the upper and under sides of the specimen, see Fig. 22 and Fig. 23. Here, a clear relationship exists between depth of the energy transformation and the change of the radiation intensity on the upper and under sides. In this regard, new possibilities emerge to monitor the deep-welding processes during NVEB-welding. 


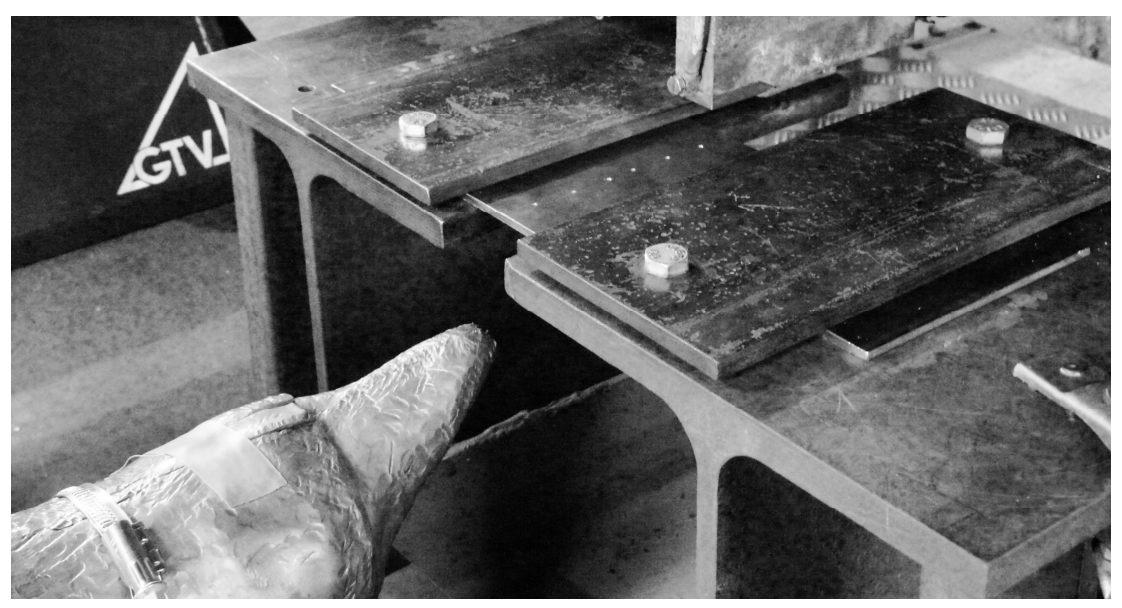

Fig. 21: Monitoring single pass welding-depth from the under side during NVEB-welding

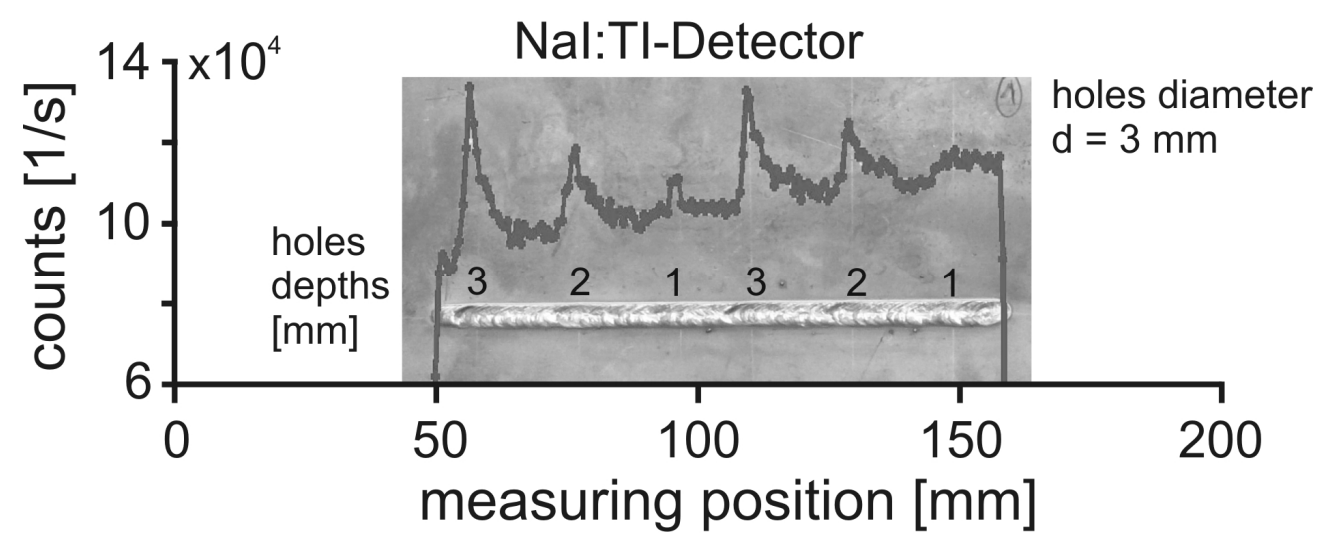

Fig. 22: Radiation intensity on the component's under side during deep welding

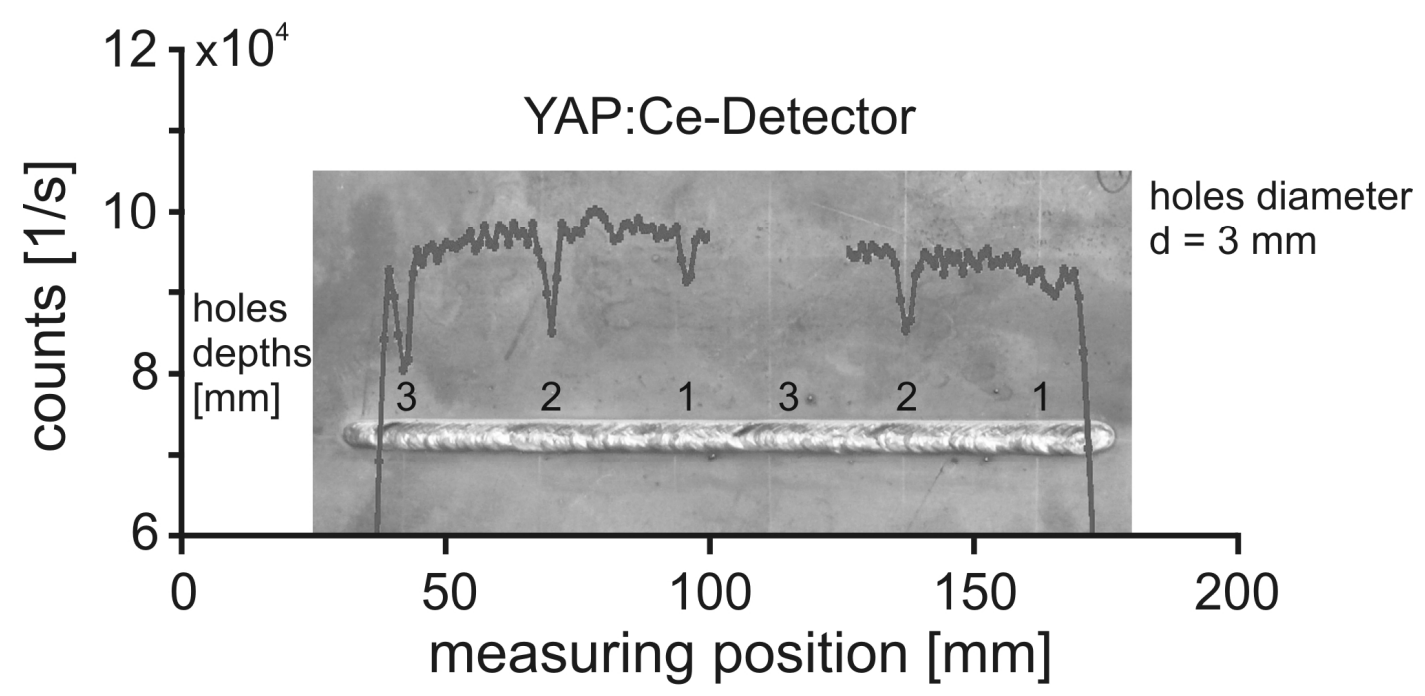

Fig. 23: Radiation intensity on the component's upper side during deep welding

The developed radiation-measuring system is based on the current energy transformation in the weld-pool and provides specific information about the fusion process. Possessing a high positioning accuracy, measuring sensitivity and measuring response, the system is suitable for online monitoring of electron beam welding processes and provides new prospects for optimising high strength welded joints via process analysis and process control. 
Weld seam defect inspection using microfocus-radioskopy. Besides the microstructure, the formation of defects in the weld region is an important criterion for assessing the strength and deformation properties of highly loaded welded joints. Guaranteeing a high seam quality requires early detection of defects in the process sequence via a process control in order to avoid weld-seam defects. Here, microfocus-radioscopy, which uses rapid image exposures, provides the prospect of inspecting welded seams online in the wake of the weld-pool and is integrated into the NVEBwelding line [35].

The component's strength and deformation properties are essentially shaped by the formation of defects and the microstructure in both the weld-seam and the heat affected zone. The formation of defects in the region of the weld-seam is therefore an important criterion for assessing the quality of the weld-seam as well as that of the strength and fatigue properties. This is of particular interest for lightweight, highly stressed structures, where high demands made on the components can only be achieved by the construction of high quality and defect-free weld seams.

Major causes of defects during electron beam welding are pore formation in the weld-pool, irregularities in the formation of the seam owing to process instability as well as high residual stresses, hardness increases and hot-cracking in the region of the seam and the heat affected zone. Flaws, impurities and material deficiencies in the seam's region lead to a reduction of the weldseam's load carrying cross-section, notch effects and, as a consequence, to stress concentrations under loading.

The microfocus-radiography provides a possibility for inspecting weld-seams and assessing flaws in the region of the weld-seam. This method is a radiographic technique where the sample is placed between the X-ray source and the verification system. The microfocus-X-ray tube has a very fine focal spot and therefore allows details to be very highly magnified and defects to be resolved. A sensitive and highly resolving X-ray beam/image converter, as the verification system within the framework of a microfocus-radiography system, enables dynamic process sequences to be observed, such as those in die-casting [36], dispersion of hard materials or an online weld-seam inspection [37] as here.

As an example, the weld-seam defect verification-sensitivity of the microfocus-radiography has been demonstrated on a few lightweight structures, such as those used in the automotive industry.

The edge formed-seam, constructed using the non vacuum electron beam equipment, on an instrument panel of thin $\mathrm{AlMg} 3$ aluminium exhibits inclusions of foreign material, sink marks, pores and fine root pores as well as weld-sputter and shrinkage cracks in the weld-seam's region, these were verified using high resolution, Fig. 24.

During laser welding of galvanised thin sheets of different grades, fusion defects as well as concealed longitudinal cracks, also occurring in the region of the laser seam, are verified by using the microfocus X-ray beam technology as sharply imaged and highly contrasted, Fig. 25 and Fig. 26. 

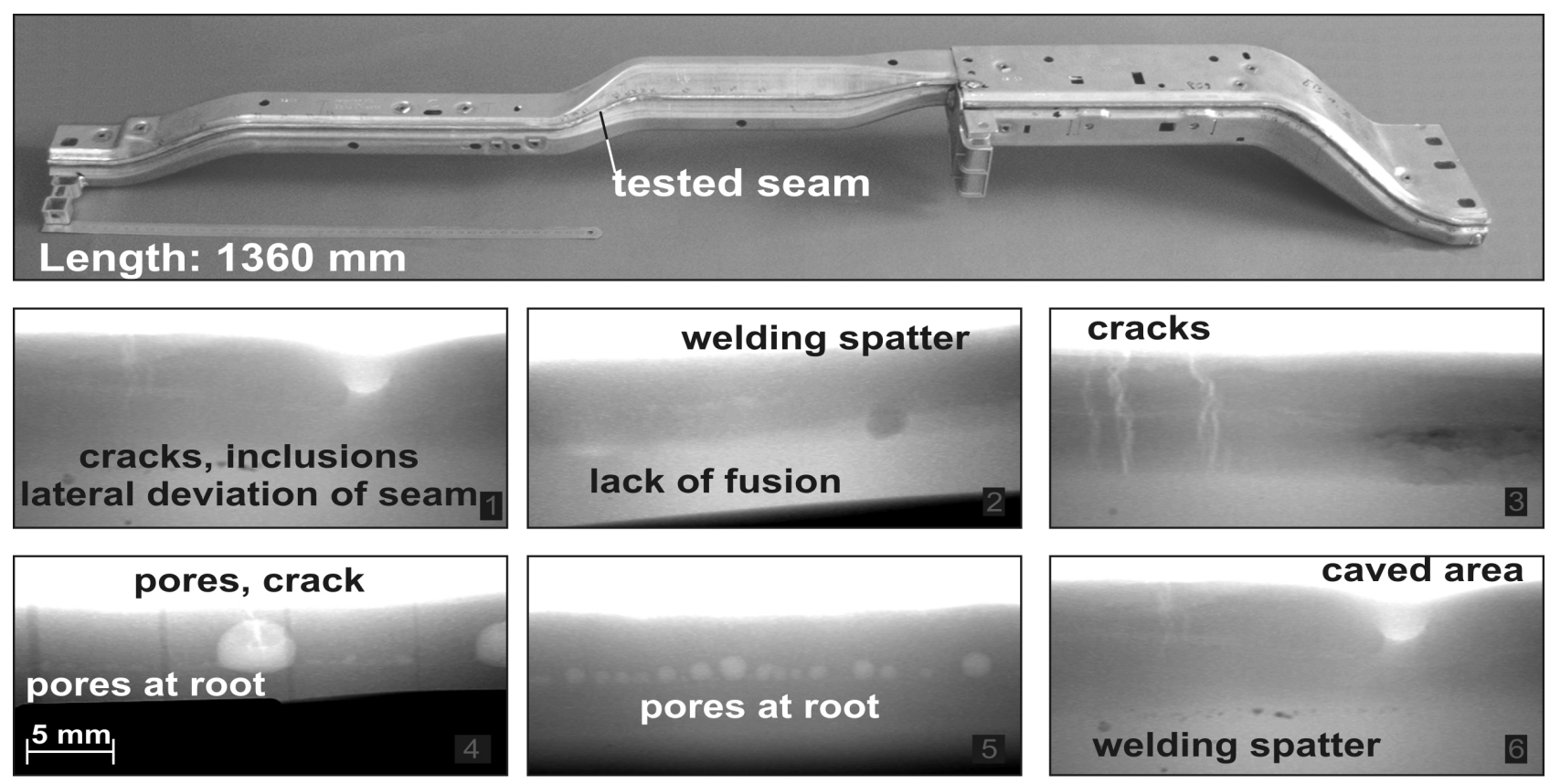

- NVEB-seam (flanged seam)

- material: AlMg3

Fig. 24: Weld-seam testing of the edge formed-seam of an instrument panel
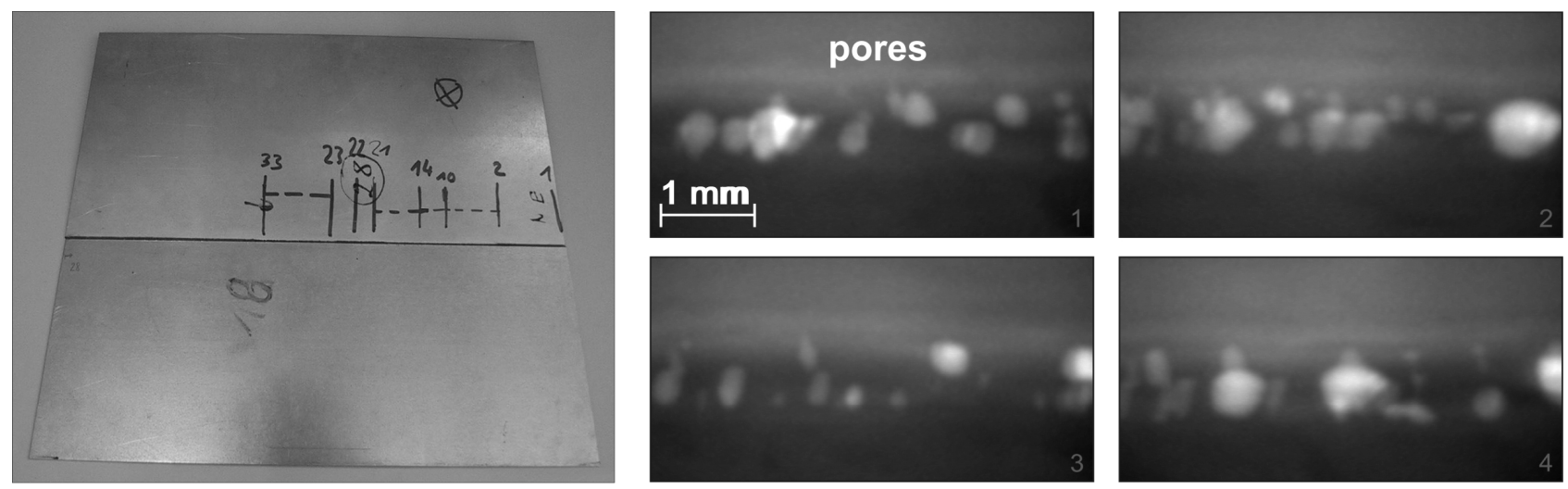

- laser welded seam (I-seam)

- material: DC04 and DP600-sheets

Fig. 25: Microfocus X-ray testing of a laser weld-seam on Tailored Blanks - weld-seam pores
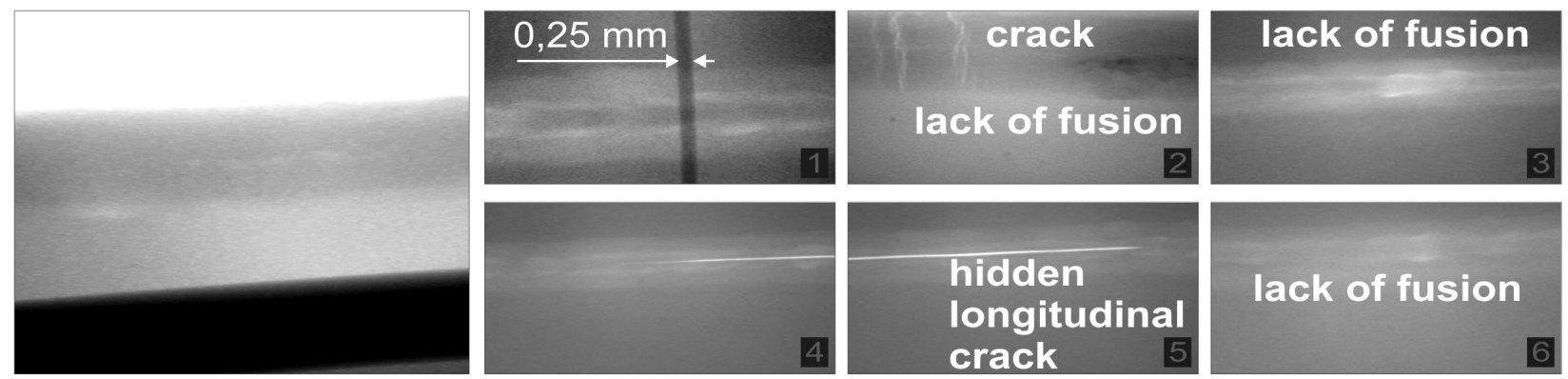

- laser welded seam (I-seam)

- material: micro alloyed- and DP600-sheets

Fig. 26: Microfocus X-ray testing of a Tailored Blanks laser weld-seam - Fusion defects, concealed longitudinal crack 
Sensor based weld-seam defect inspection using remote field eddy-current technology. From the perspective of the technical and financial outlay as well as operating under manufacturing conditions, a sensor based measuring technology has clear advantages over radiographic inspections. Using high defect sensitivity and penetration depths, remote field eddy-current testing offers the prospects for rapidly detecting defects in the weld-seam region under manufacturing conditions. The remote field eddy-current (RF-EC) technology operates with separate and screened excitation and measuring coils. The technology was developed at the IW within the framework of fundamental investigations into both defect testing in thick-walled austenitic components as well as weld-seam testing of light metals and is based on FEM-simulated computation [38, 39].

conventional ec-testing

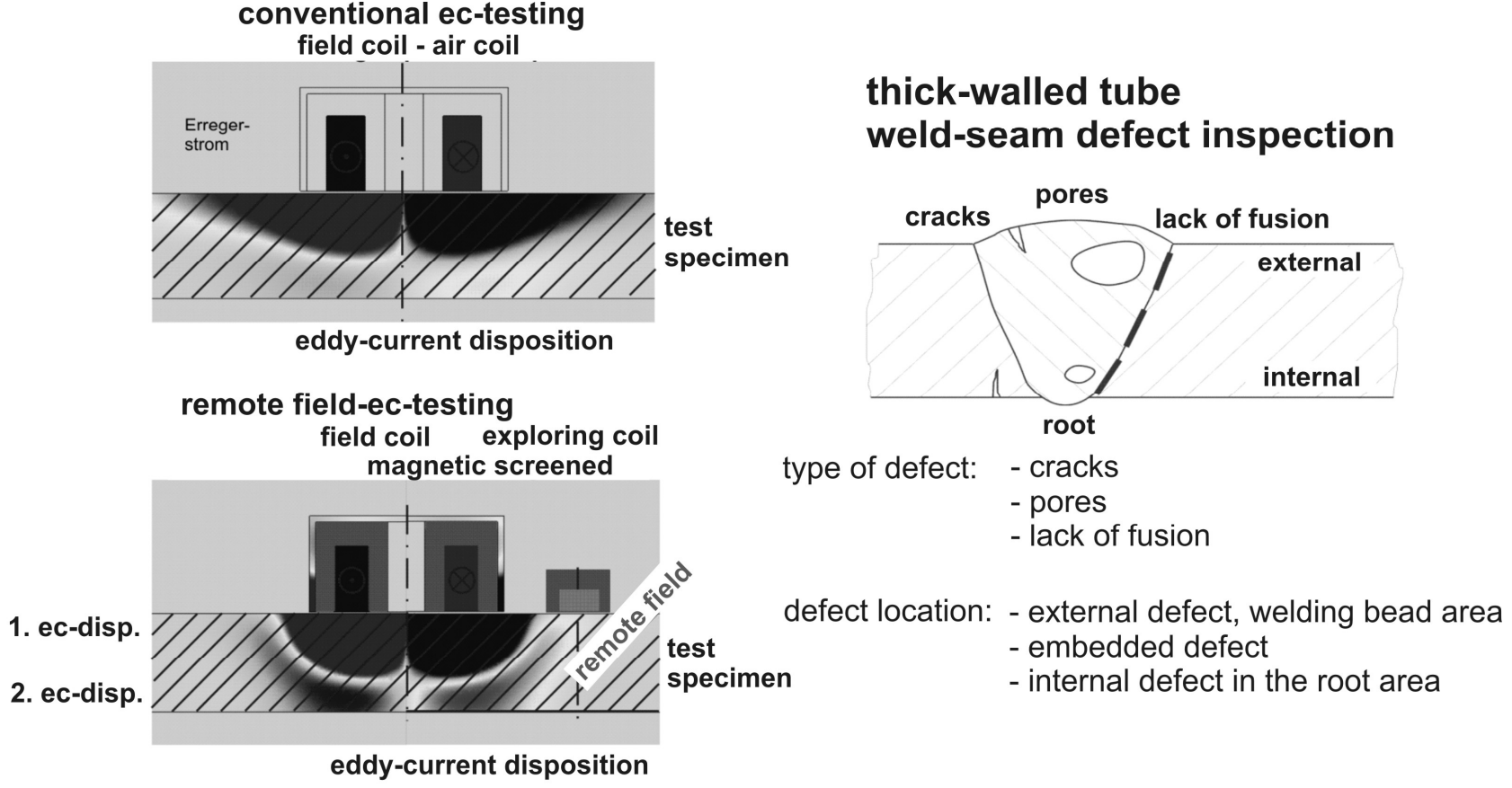

Fig. 27: Eddy-current distribution: conventional and remote field eddy-current testing

Simulated computations, carried out to compare different types of coil systems, have demonstrated that in conventional eddy-current testing, using either non-cored or cored coils, the eddy-current distribution below and also next to the excitation coil is well formed near to the surface. Another secondary eddy-current distribution possessing a phase angle of approx. $180^{\circ}$ and generated from the primary eddy-current distribution's field emerges at greater depths in the component and at lower intensities. However, this formation of secondary eddy-currents deep in the component is largely eclipsed by the primary eddy-current distribution, see Fig. 27. By using magnetically screened excitation coils, the magnetic flux's path, and thereby the concentration of the eddy-current distribution beneath the excitation coil, is obtained via an increased permeability. By concentrating the primary eddy-current distribution, the secondary eddy-current distribution is also intensified and has an almost homogeneous eddy-current density over the component height which extends up to the component's surface, see Fig. 27. 


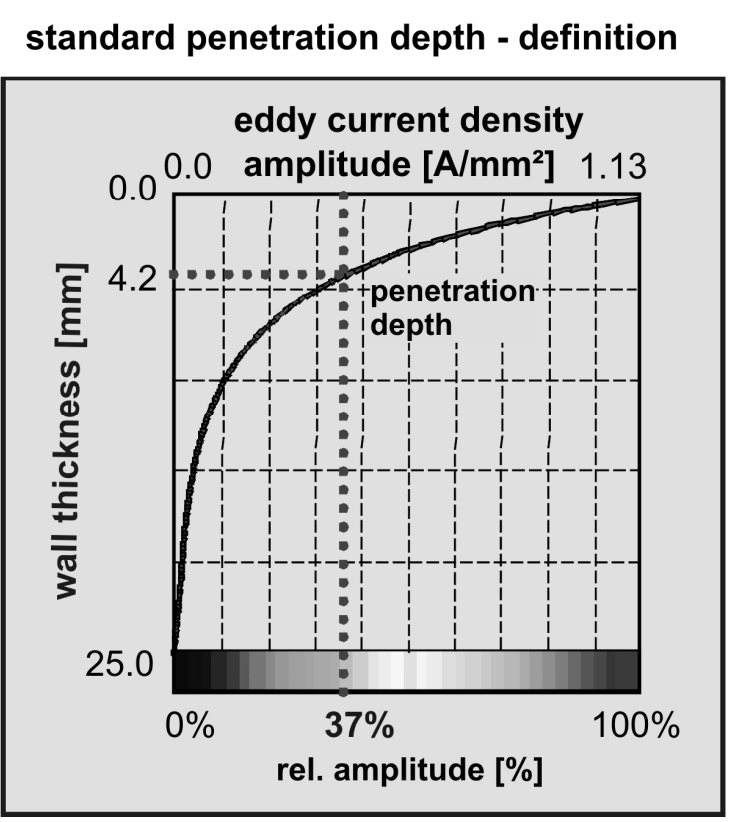

horizontal position of the standard penetration depth [mm]

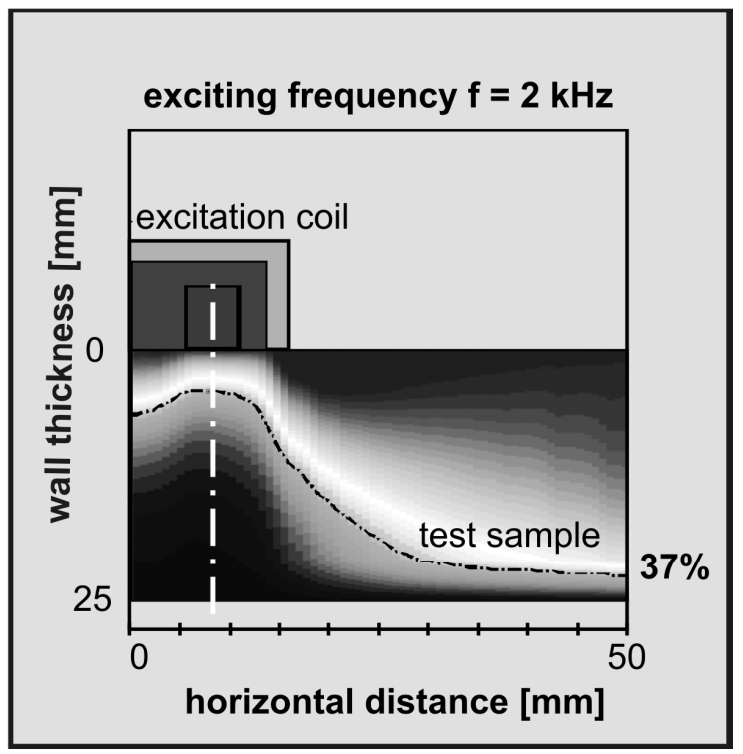

Fig. 28: Standard penetration depth

A measure of the formation and homogeneity of the eddy-current distribution in the test piece is the eddy-current's standard penetration depth. This specifies the distance from the surface at which the eddy-current density has dropped to 1/e, which corresponds to approx. $37 \%$.

It is clear from Fig. 28 that the penetration depth beneath the excitation coil is very low and assumes much larger values with increasing distance. This is due to the fact that although the eddycurrent's density becomes lower with increasing probe distance, it assumes a more homogeneous distribution.

Here, the formation of the eddy-current distribution in the test piece is essentially dependent on the coil geometry, the testing parameters as well as the component geometry and the material properties.

This secondary eddy-current distribution is accessible from the components surface via the field effect next to the excitation coil and, corresponding to its development, offers the prospect for uniformly assessing weld-seam defects over the weld depth.

To verify the results of the FEM-simulation, experimental investigations were carried out on an aluminium plate with a $5 \mathrm{~mm}$ wall-thickness. $1.5 \mathrm{~mm}$ diameter test holes were drilled into the plate to depths of 1,2 and $3 \mathrm{~mm}$ on it upper and under sides. The test frequency was varied from $1 . . .3 \mathrm{kHz}$ and the probe's distance between the excitation and measuring coils ranged from 0 to $10 \mathrm{~mm}$. 

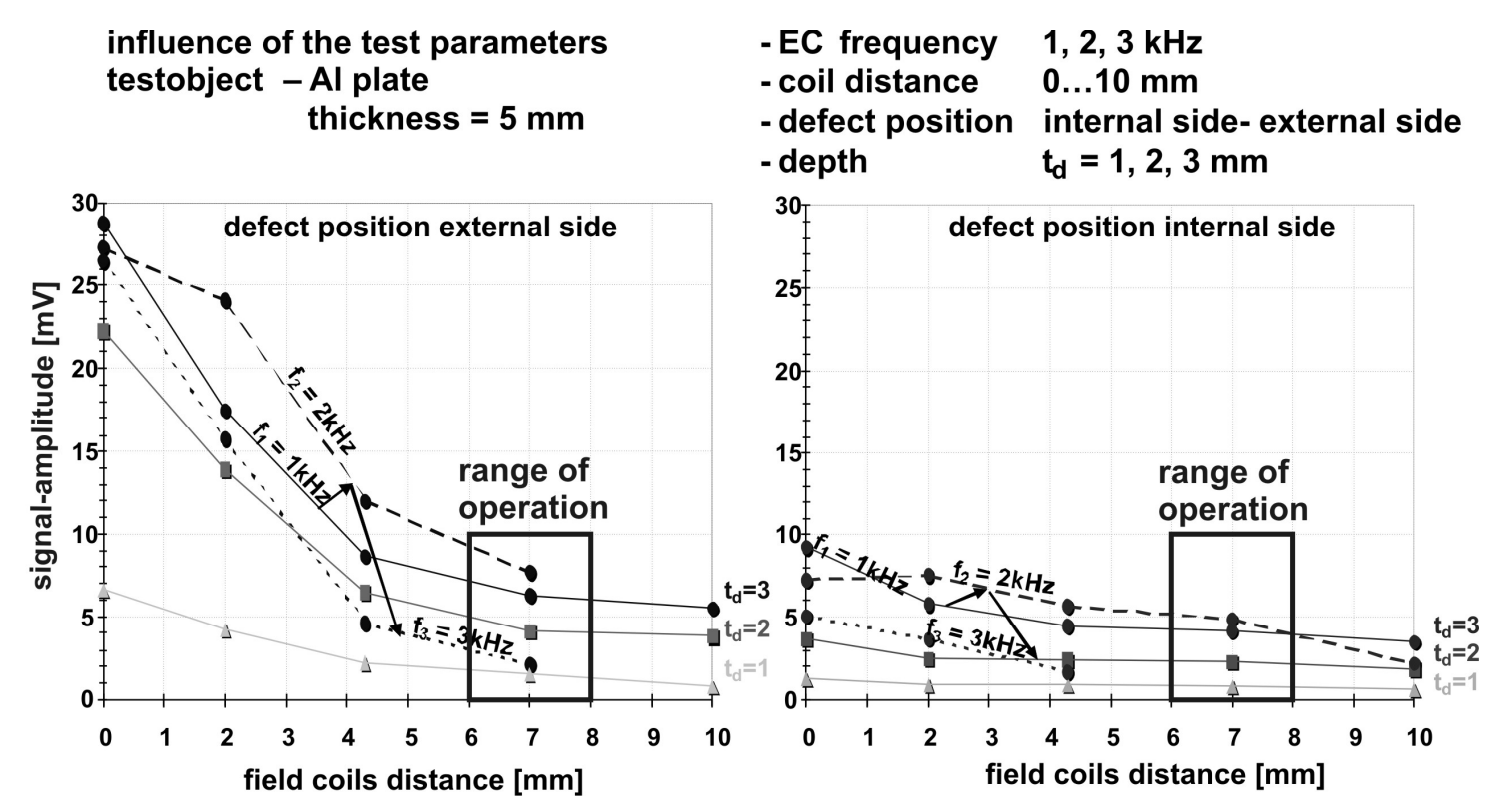

Fig. 29: RF-EC-tests - amplitude for internal and external defects

With regard to the defect's situation, external defects are much more sensitively verified at lower coil distances. As the simulated computations had shown, an increase of the test frequency initially leads to an improvement of the verification sensitivity at low coil distances but to a significant decrease for greater coil distances. This can be attributed to the increasing sub surface formation of the eddy-current distribution in the component with rising test frequency.

At a test frequency of $1 \mathrm{kHz}$ and a coil distance of $7 \mathrm{~mm}$, internal and external defects are established which have a similar signal amplitude and one which is approximately proportional to the defect depth. This is due to the almost homogeneous eddy-current distribution over the plate thickness, Fig. 29. As the simulated computations had also shown, here the phase angle of the measuring signal is explicitly related to the defect position. Small internal and external defects are detected at these test frequencies under phase angles of approx. $50^{\circ}$ and $140^{\circ}$, respectively. With increasing defect depth, the phase angles approach a mean value of $90^{\circ}$ at which the explicit correlation is maintained, Fig. 30 .

- EC frequency
- coil distance
- defect position
- depth

$1,5 \mathrm{kHz}$

$0 . . .10 \mathrm{~mm}$

internal side external side $t_{d}=1,2,3 \mathrm{~mm}$

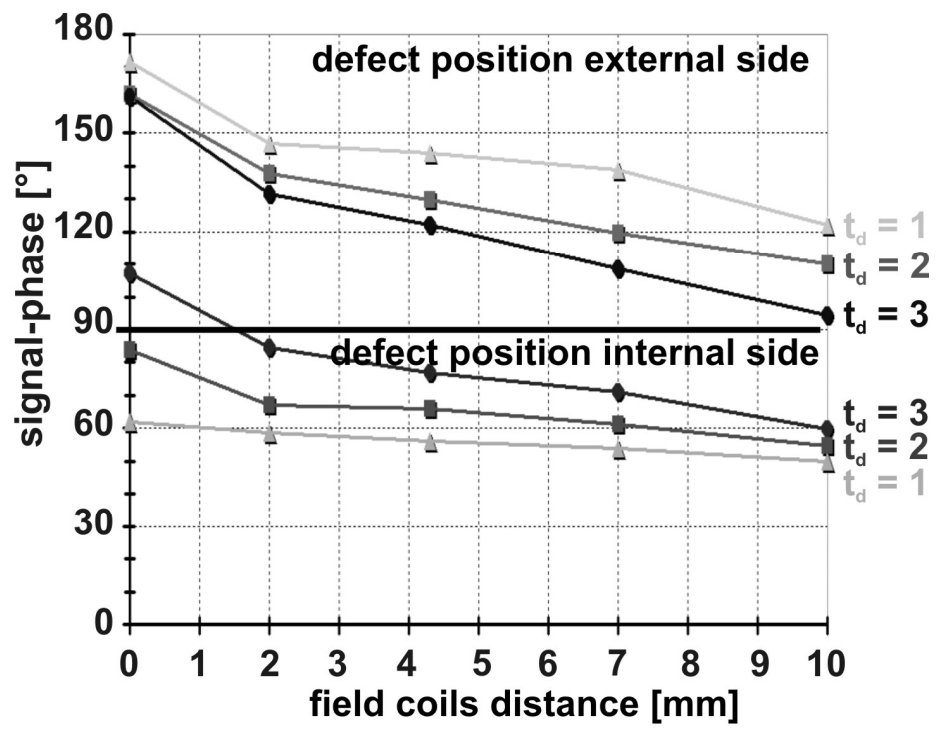

Fig. 30: RF-EC-tests - signal-phase for internal and external defects 
In view of the practical applications of the remote field eddy-current technology for weld-seam defect inspection, the test set-up is designed by means of the FEM-simulated computations and the test parameters are optimised in trial tests on test pieces containing specifically introduced test defects. Inspections of components and weld-seams for defects were carried out on tubes and profiles of aluminium and austenitic materials having wall-thicknesses ranging from 1 to $20 \mathrm{~mm}$.

The results of investigations from the remote field eddy-current testing during longitudinal seam welding of aluminium tubes are depicted as an example. The remote field eddy-current sensor with screened excitation and measuring coils, which lie separated in series longitudinal to the tube, are located on a rolling sensor-carrier and is locally aligned and positioned to the weld-seam region, Fig. 31 .

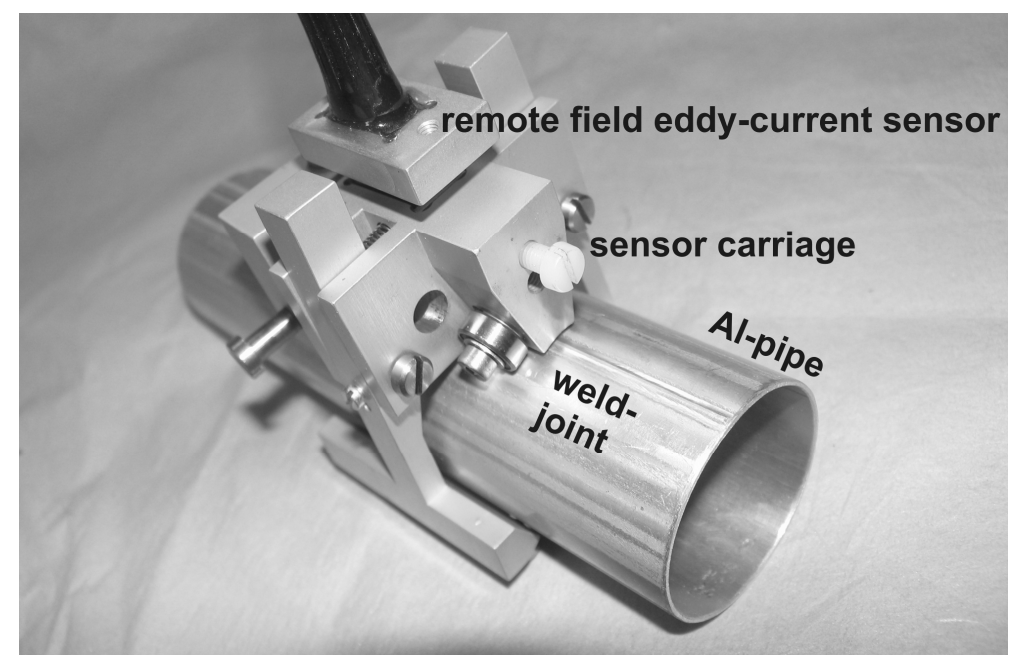

Fig. 31: Aluminium tube longitudinal weld-seam testing using remote field eddy-current sensor

During longitudinal seam-welding of tubes, weld-seam defects, such as fusion defects, pores or cracks in the seam region, can occur as a consequence of interference influences owing to foreign material or damage to the strip's edge.

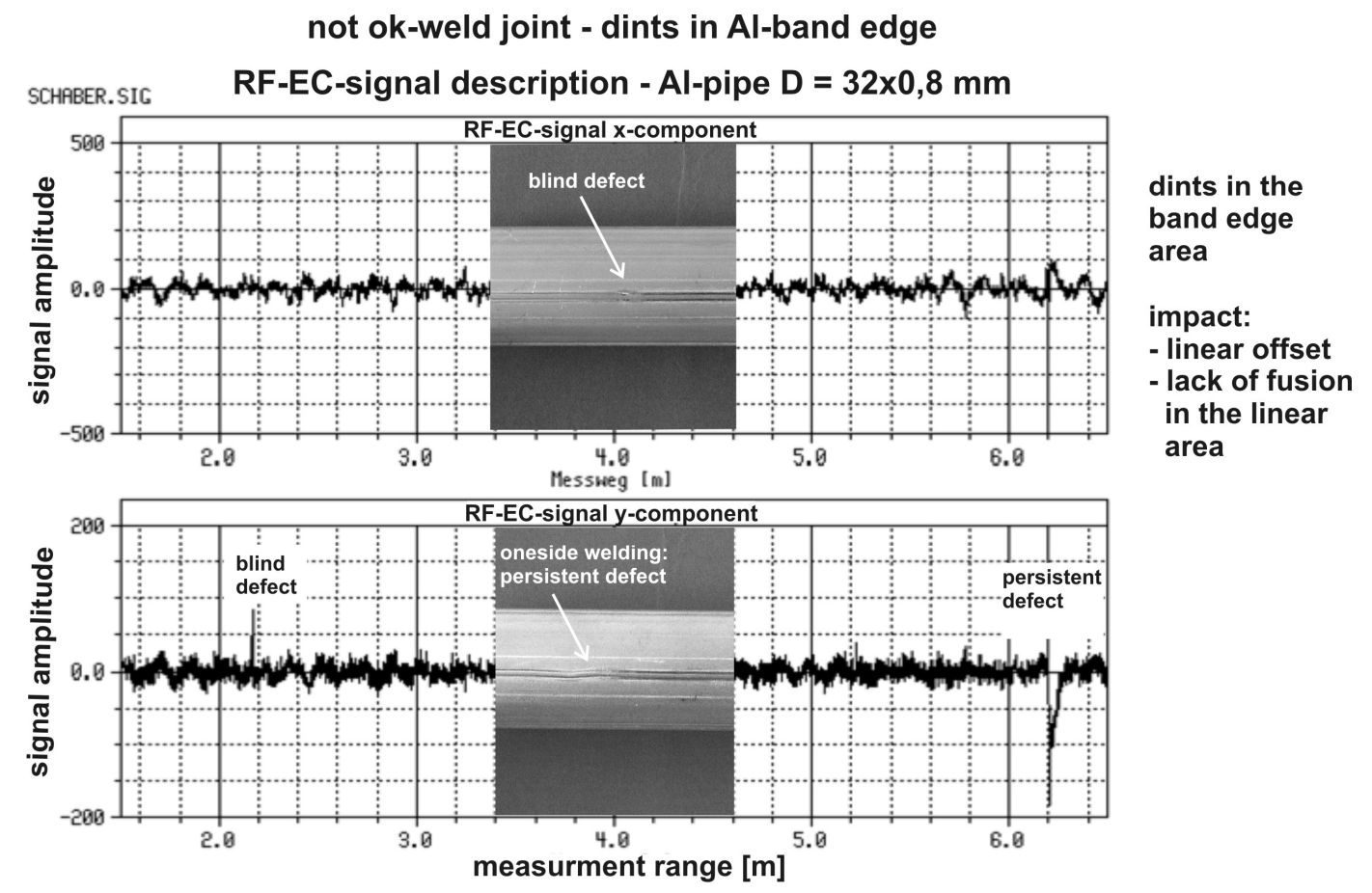

Fig. 32: Defect classification during longitudinal seam-welding of tubes using remote field eddycurrent technology 
Using a remote field eddy-current probe, which was adapted to the testing task and locally aligned to the weld-seam region, concealed internal, embedded and external defects are sensitively verified in the eddy-current signal amplitude with respect to their formation and in different signal phase positions with respect to their depth location. This is manifested in the signal-distance curve in the tube's longitudinal direction shown in Fig. 32. Starting from a signal-noise level, which is shaped by the quality of the weld-seam, the defect's depth location is related to the signal phase and is accordingly manifested in signed, positive and negative values, signal changes.

\section{Local setting of gradient material properties}

In direct relation to the subject matter of the CRC 675 [40], a further task in the subproject C4 was the setting of gradient material properties by using laser and electron beam technologies for manufacturing structures possessing modified strength and deformation properties, Fig. 33.

Corresponding to the basic character of these investigations, a concept was developed to locally calibrate component properties, Fig. 34.

\section{high powered fibre laser Ytterbium-laser wavelength focal-spot diameter

$$
\begin{aligned}
\lambda & =1075 \mu \mathrm{m} \\
\mathrm{d}_{\mathrm{St}} & =10 \ldots 500 \mu \mathrm{m} \\
\mathrm{P}_{\mathrm{St}} & =200 \mathrm{~W}
\end{aligned}
$$

NVEB-electron beam equipment PTR NV-EBW 25-175

accelarating-voltage electron current beam power working range

$$
\begin{aligned}
& \mathrm{U}=175 \mathrm{kV} \\
& \mathrm{i}_{\mathrm{e}}=140 \mathrm{~mA} \\
& \mathrm{P}_{\mathrm{St}}=25 \mathrm{~kW} \\
& \mathrm{a}=10 \ldots 50 \mathrm{~mm}
\end{aligned}
$$

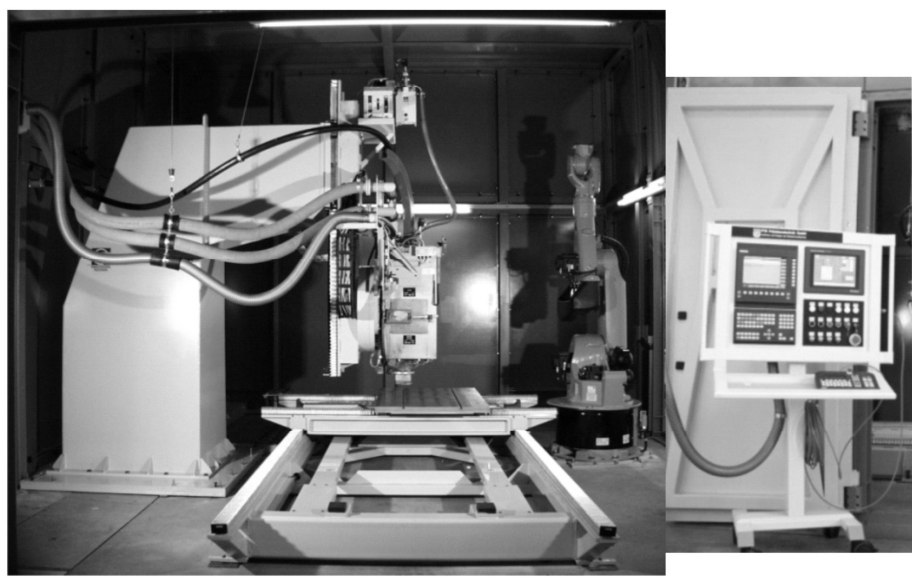

Fig. 33: Local heat treatment using fibre-laser and NVEB equipment

In view of the indicated objective, investigations were carried out to locally heat treat and to locally influence material and component properties using electron beam and laser technologies. The main concern of the investigations is the local heat treatment of sheet specimens, which are suitable for setting a fine grained, work hardened rolled microstructure by means of subsequent heat treatment. For this purpose, AlMgSi light-metal alloys, austenitic chrome-nickel steels [37, 39 and 40] and high strength, residual-austenitic steels (RA-steels) containing manganese were processed [35, 37, 42 and 43].

As a result of cold-roll forming, the sheets are cold-worked. A local heat treatment is carried out in parallel and structured lines in order to grade local regions with material, which possess lower hardness values and strength or increased ductility, via recovery, recrystallisation and microstructural transformation. Here, the intensity and depth effect of the local heat treatment can be individually adapted to correspond to the specific requirements of the material and component. 


\section{concept for locally setting component properties using beam technology}

- specifically influencing material properties

- materials
- work-hardening effects
- microstructure formation

$\Rightarrow$ aluminium, magnesium, steels, austenitic steels, multiphases steels

$\Rightarrow$ phase development, flaws, dislocations,age-hardening

$\Rightarrow$ stress-rekieving, recrystallisation, microstructural transformation

- qualification of the NVEB and laser technologies for local heat treatment

- specifically varying the beam parameters $\Rightarrow$ working distance, power, speedt

- influence on the microstructure $\quad \Rightarrow$ regeneration - relieving residual stresses,

and material properties rearranging lattice sites

$\Rightarrow$ recrystallisation - annihilation of dislocations and vacancies,

- structured heat treatment

$$
\Rightarrow \text { fusing } \quad \text { - microstructural transformation }
$$

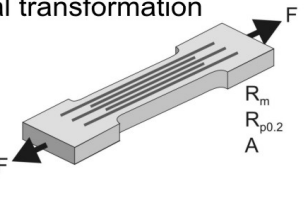

- detection and description of locally modified component properties

- linking of high strength with ductile component domains

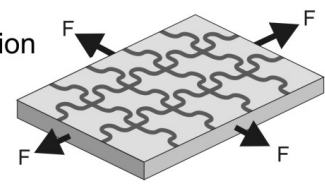

Fig. 34: Setting material properties using local heat treatment

Locally structured heat treatment using beam technologies. Specifically setting material parameters is to be achieved in conjunction with, for example, cold working or martensitic formation by means of a specified heat treatment. The influence of a definite heat treatment as a function of tempering temperature on the mechanical material parameters, such as yield stress, tensile strength and fracture strain is depicted in Fig. 35 using the austenitic material 1.4310 as an example. Also shown is the local heat treatment of a specimen using a fibre-laser and the detection of local material properties using eddy-current scanning technology. Using this technology, prospects exist for locally detecting the material's state in the component edge region at a high resolution and of comparing this with a reference value.

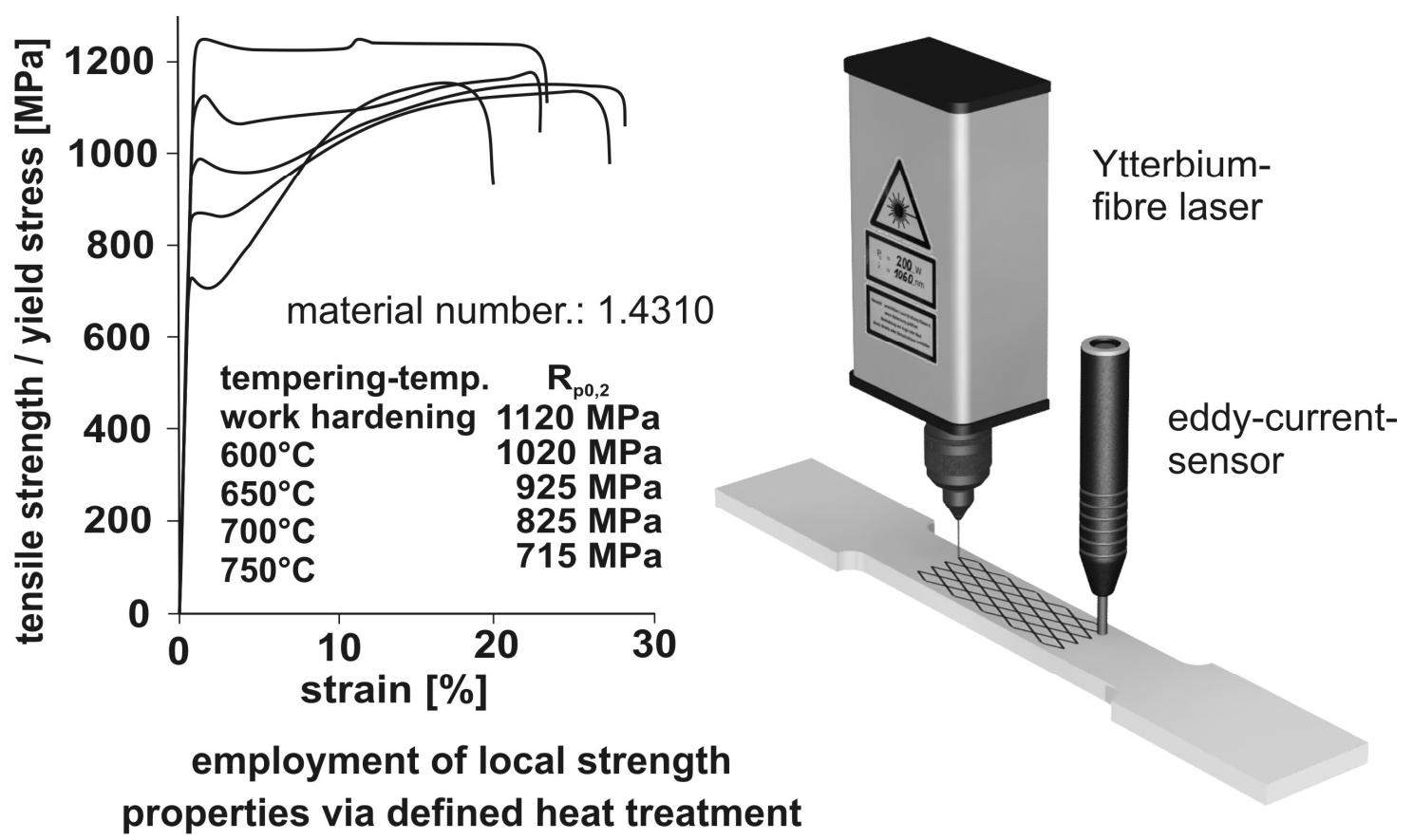

Fig. 35: Structured heat treatment using beam technology

As an example, the results from cold worked light-metal and steel materials by cold-rolling and then locally carrying out a structured heat treatment are depicted in Fig. 36. The specimen's local heat treatment can be discerned in a linear or cross-hash pattern. The degree of microstructural change and the penetration depth of the local heat treatment become clearer in metallurgically prepared 
samples. Quantitative statements about the local changes of the material parameters in the affected zones of the treated lines can be obtained via a micro-hardness measurement on the metallurgical sample. According to the extent of cold-working and the intensity of the heat treatment, a more of less large decrease in the hardness value is obtained in the treated line.

locally heat treatment on cold work-hardened flat specimens, verification of the strength and ductility properties

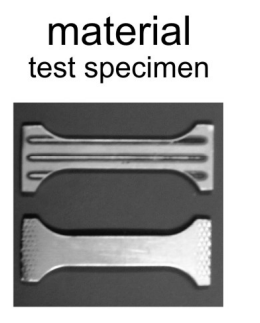

material: high-strength martensitc steel

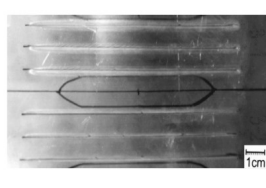

material: AlMgSi (line design)

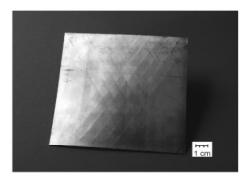

material: AlMgSi (rhombus design)
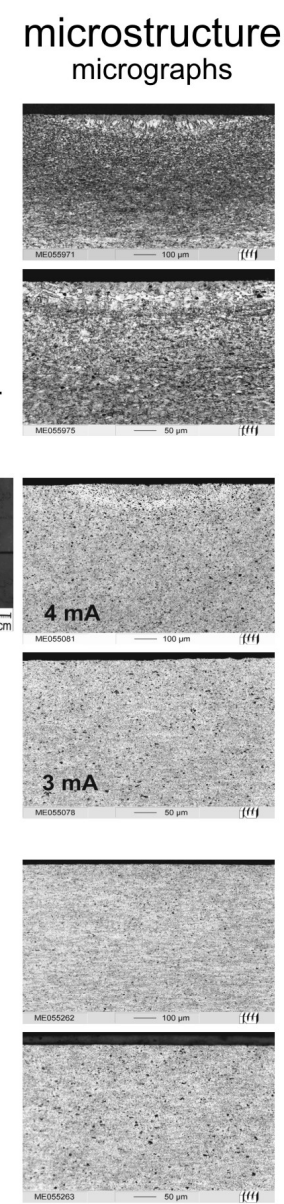
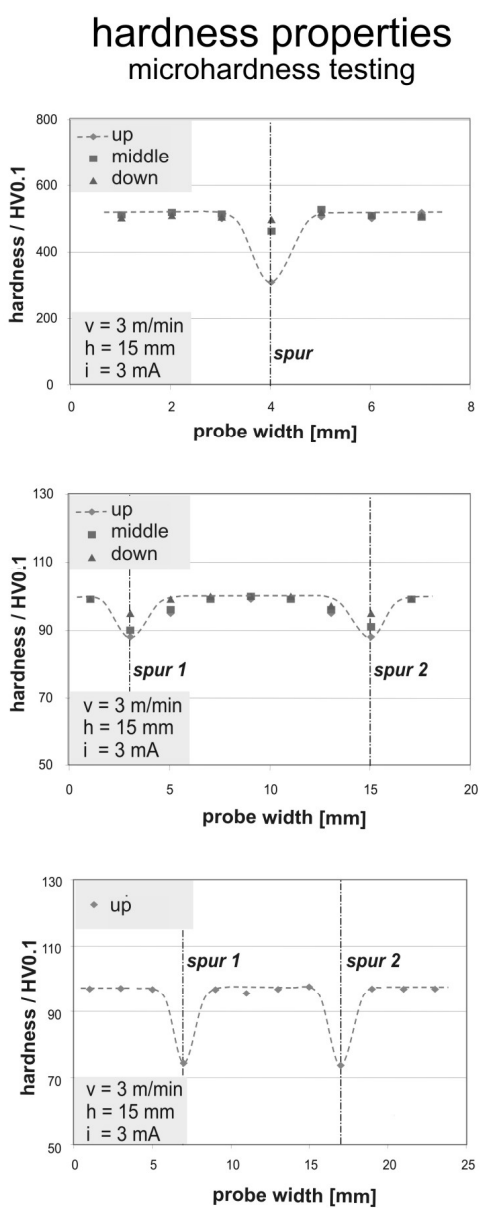

mechanical properties tension test
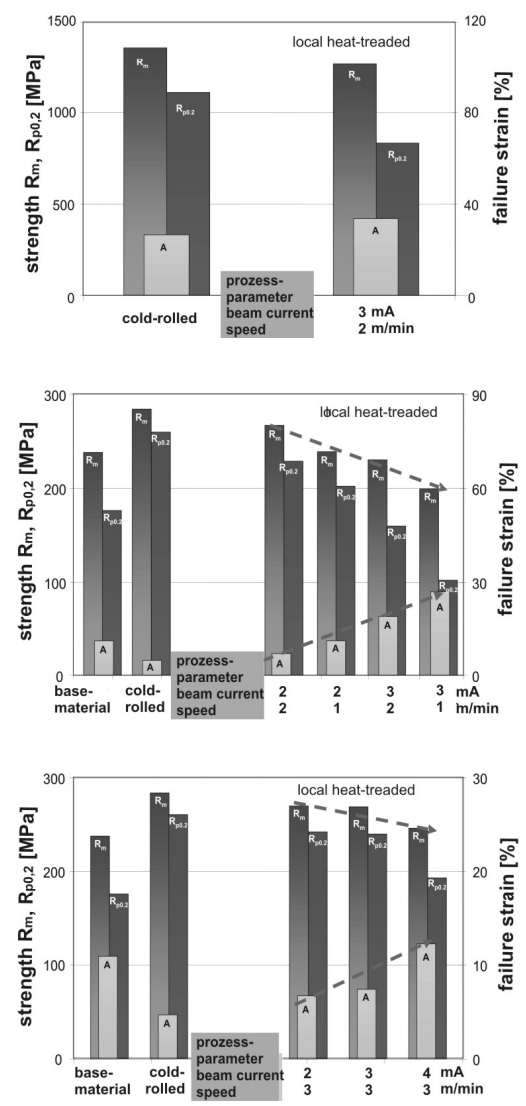

Fig. 36: Setting of the components properties using the electron beam

Regarding the modification of the strength and deformation properties, an overall evaluation of the component's properties resulting from the cold-working and the local heat treatment is provided by tensile tests. In comparison to the basic material, an increase in both yield stress and tensile strength for a significant reduction of the fracture strain is obtained by means of the cold-rolling. In contrast to this, besides a slight decrease in the strength properties, subsequent local heat treatment of the cold-worked specimens produces a significant increase in fracture strain. In particular, apart from high strengths, cold-worked components also exhibit high fracture strains following structured heat treatment due to the cold-worked and ductile material regions.

Stress-designed anisotropic material properties. Subject to the requirements of resource conservation, lightweight components and structures are gaining increasing importance. With regard to this, a stress-designed configuration of highly loaded components, which corresponds to the actual loading case and the principle stress directions, requires the local setting of directionally dependent, anisotropic material properties. This can be achieved via a locally structured heat treatment of the globally cold-worked materials by means of linking high strength elemental domains, which are embedded in ductile edge regions, to absorb the principle stresses. These 
transverse ductile regions relieve the residual stresses via deformation and thereby lower the sensitivity to crack initiation.

In order to detect and verify the influence of the local structured heat treatment on both the formation of the microstructure in the affected zone as well as the material properties, investigations on cold-worked aluminium and austenitic steel sheets were carried out. A controlled, uniform and local introduction of energy into the individual geometric structures without pronounced contact burning requires program-controlled automation of the beam equipment, Fig. 37.
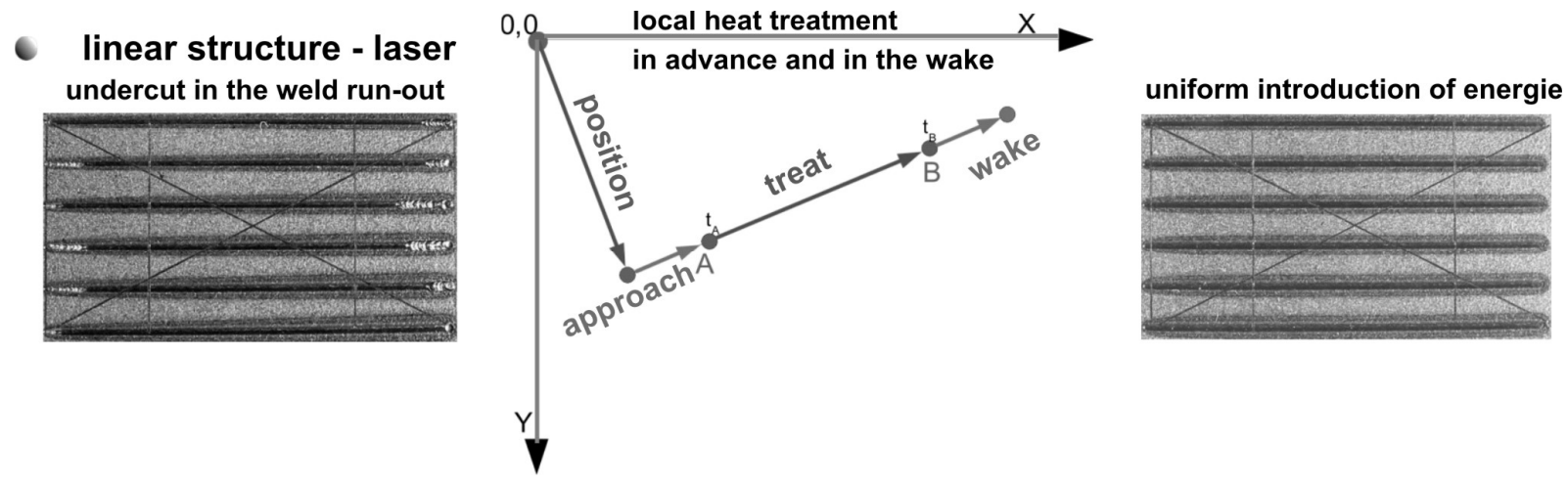

Fig. 37: Automated beam technology for local heat treatments

A specific local heat treatment of the components, dependent on the material properties, can be achieved by varying the process parameters: beam power, beam diameter or focal point as well as the processing speed. Of interest here, is the level of the microstructural changes across the line's width and the penetration depth into the material as well as the material property changes along the processed line.
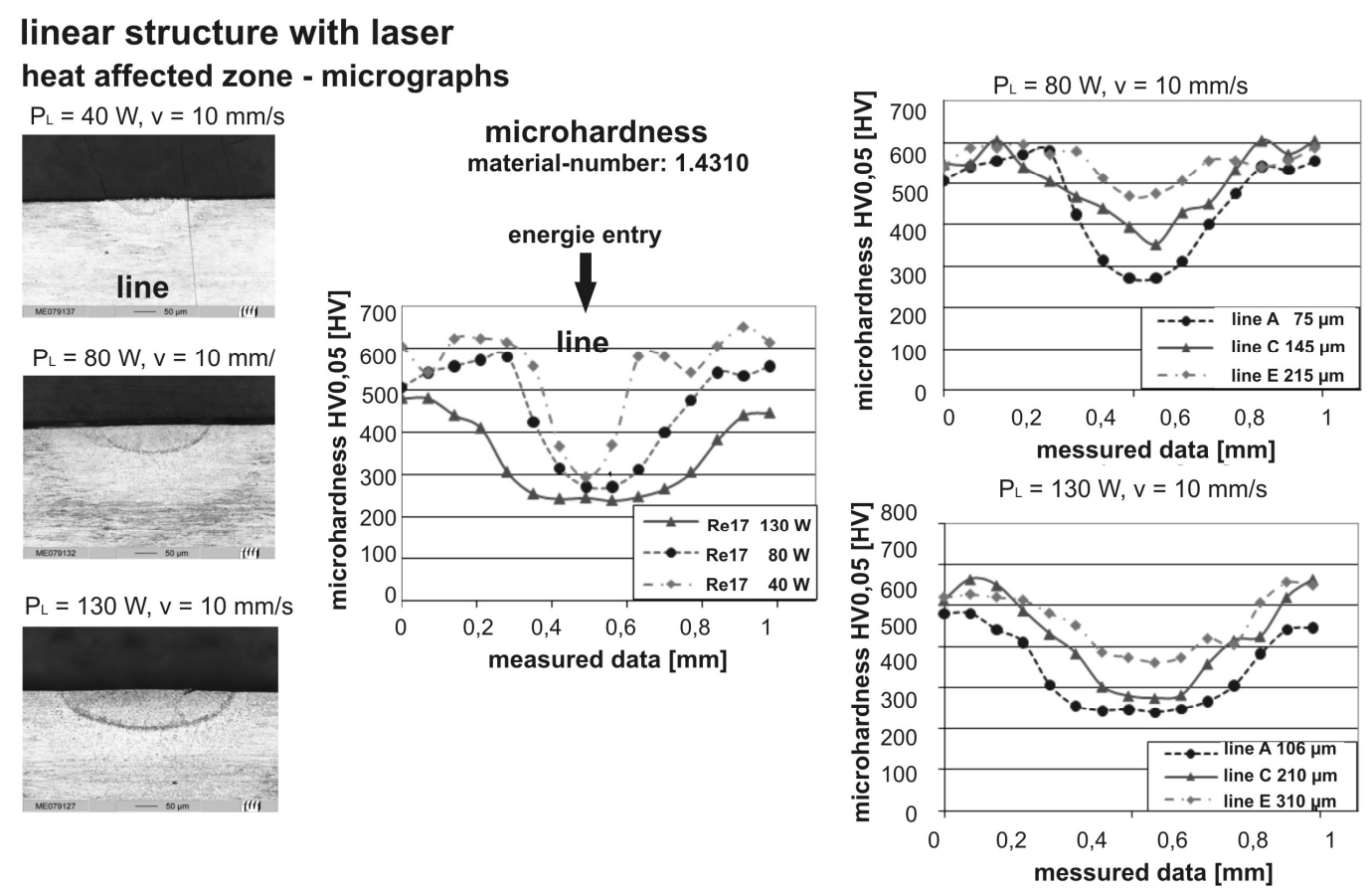

Fig. 38: Gradient material properties in the region of a heat-treated line structure

On locally setting ductile material regions with improved deformability, material damage or embrittlement are to be avoided as much as possible. Investigations carried out to locally heat treat different materials by varying the beam's process parameters have shown, on the basis of metallurgical samples and microhardness measurements, that the influence on the level of 
microstructural change and on the affected zone of the processing line is broad ranging in width and depth, Fig. 38.

To set anisotropic component properties, the local heat treatment was performed using laser- and NVEB beam technologies in geometric patterns of lines, cross-hash and puzzle-like structures, Fig. 39. The changes, which were obtained via local structured heat treatment, in the mechanical/technological material properties are depicted in Fig. 40, using cold-rolled, high strength austenitic steel as an example. By means of the heat treatment, which was performed using the electron beam in a cross-hash pattern subject to specified process parameters, the martensite which was formed as a result of cold forming is tempered and is transformed back into austenite at higher processing temperatures.

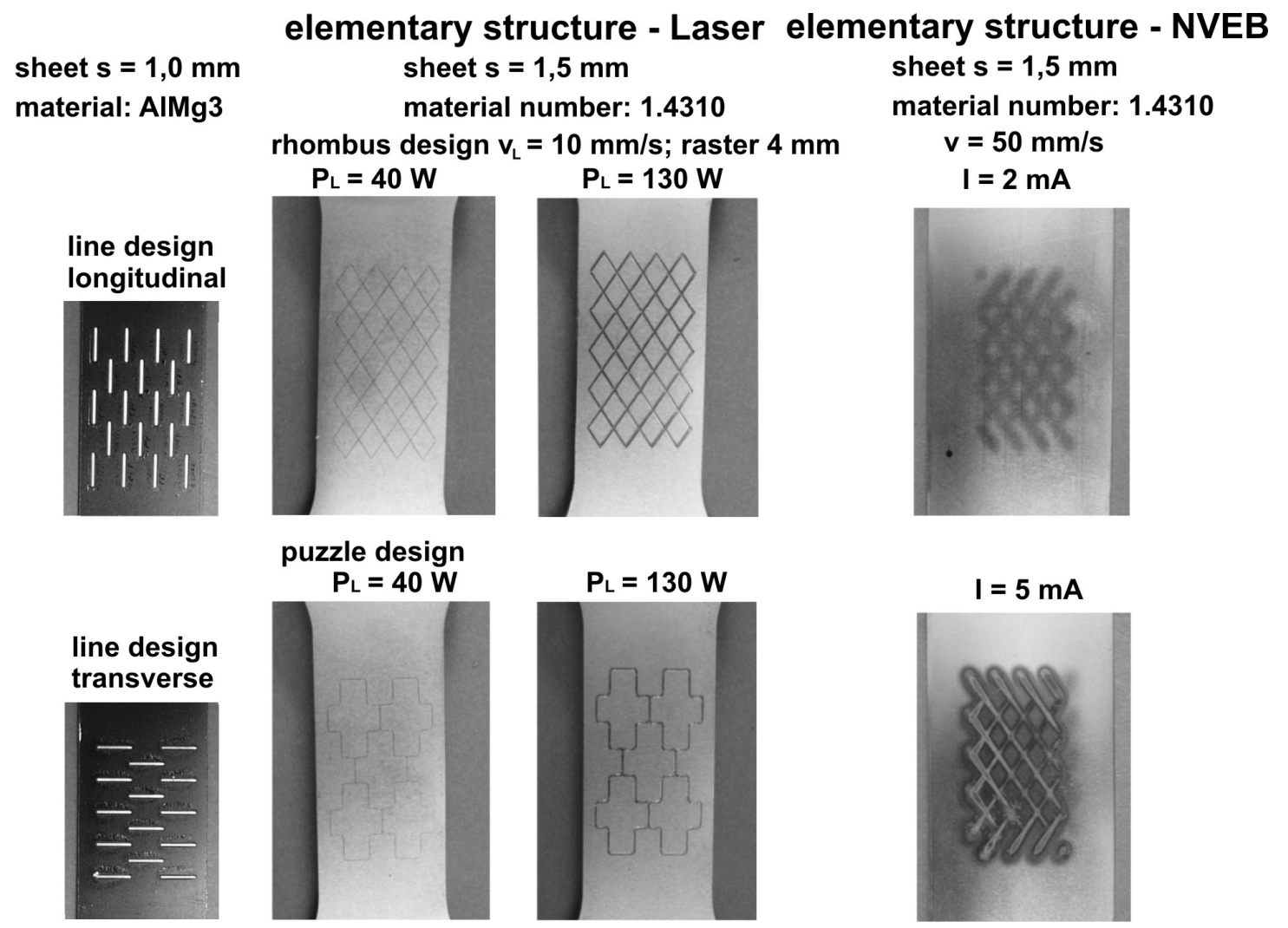

Fig. 39: Structured local heat treatment

By this means, a low increase in the tensile strength and fracture strain is obtained at low beam powers and processing temperatures by stress relieving the material. At higher beam powers and processing temperatures, the local martensitic transformation leads to a significant reduction of the yield stress as well as an increase in the fracture strain each of $\sim 27 \%$ for a slight reduction in the tensile strength of $\sim 13 \%$, Fig. 40 . 


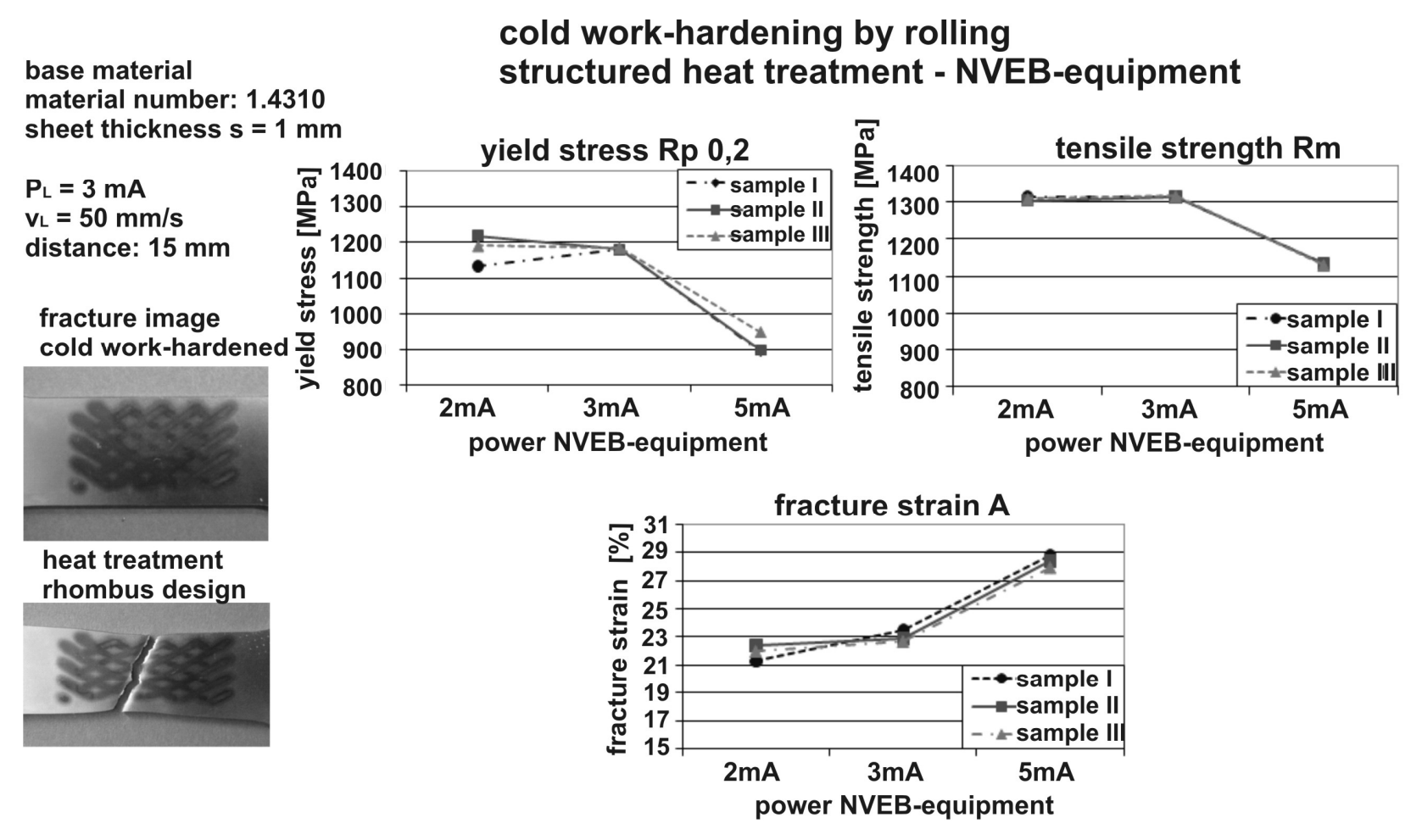

Fig. 40: Changes in the mechanical/technological material properties

Apart from the material and the local heat treatment parameters, the directional dependent component properties are modified by the direction of the line structure. For a component loading with the principle stress direction parallel to the line structure, the line of force in the component is essentially transmitted by the neighbouring, untreated higher strength structural elements. Contrary to this, for a load alignment and principle stress direction perpendicular to the line structure, the line of force is entirely transmitted across the heat-treated line structure. Subject to a loading direction perpendicular to the line structure, the component properties are shaped by the modified material properties in the line structure. In this loading case, premature local plastic deformation occurs in the heat treated regions by means of the loading stresses exceeding the locally reduced value of the yield stress.

In order to systematically investigate the influence of the line structures on the anisotropic component's properties, line structures with various heat treating parameters were introduced into tensile specimens of aluminium and austenitic steel materials longitudinal and transverse to the loading direction. In their initial state, the sheets were globally cold-worked by cold-rolling at plastic deformation level of $10 \ldots 30 \%$. The line structures were introduced via a local heat treatment using a defocused fibre-laser or an electron beam in unbroken, staggered $5 \mathrm{~mm}$ long lines, Fig. 39. The results of the tensile tests are depicted in Fig. 41, using the cold-rolled aluminium sheet as an example. A global cold work-hardening at a plastic deformation forming level from $10 \%$ to $30 \%$ produces an increase in the tensile strength from $200 \mathrm{MPa}$, in the initial state, to $250 \mathrm{MPa}$ and a lowering of the fracture strain from approx. $15 \%$ to $5 \%$. Performing a local heat treatment in a line structure using a fibre-laser at low laser power produces a further slight increase in the tensile strength and fracture strain owing to the stress relieving. 

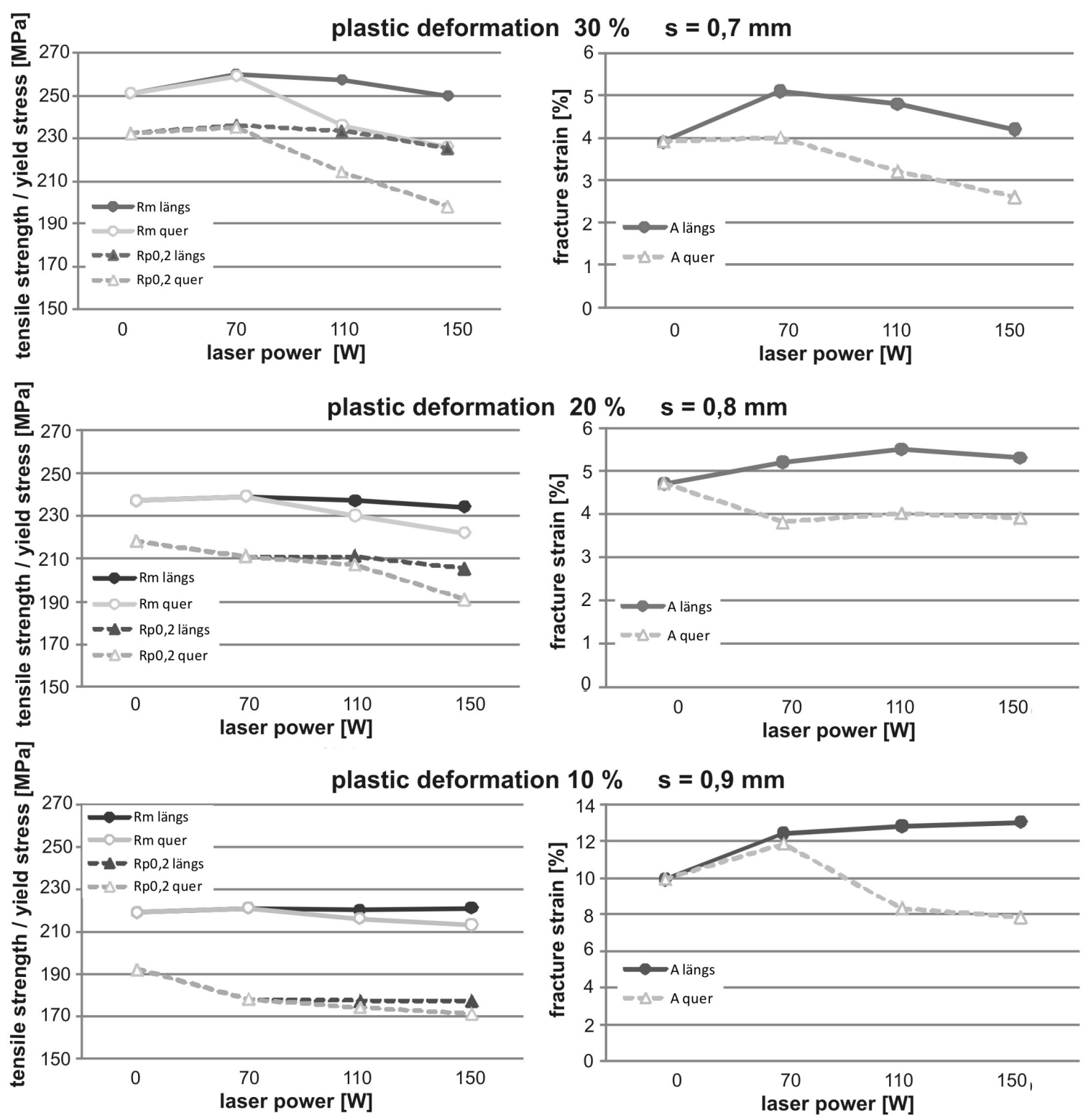

Fig. 41: Influence of the work hardening and the local structured heat treatment on the anisotropic

Higher laser power and processing temperatures lead locally to the microstructure's recrystallisation and accordingly to a somewhat lower tensile strengths and yield stresses and almost unchanged fracture strains. The previously discussed relationships between the direction of the line structure and the loading direction were also confirmed at larger laser powers and local microstructural changes. For a loading direction parallel to the direction of the line structure, the influence of the local heat treatment on the strength parameters is only minor. In contrast to this, a significant lowering of the tensile strengths and yield stress values is found for loading perpendicular to direction of the line structure with increasing local heat treatment. This anisotropic component behaviour is shaped by the alignment of the line structure and can be influenced via the level of global work-hardening and local heat treatment. Thus, using a local structured heat treatment of component's work hardened regions, novel possibilities emerge to also calibrate directional component parameters and to individually adapt these to the predominate loading cases and loading profiles. 


\section{Summary}

Subject to the objective of further qualifying the NVEB-welding technology, which possesses a narrow weld and heat affected zone, for highly loaded components, a process technology was developed to recognise weld-gaps and to position beams, to monitor online the weld-pool and the keyhole formation as well as to inspect defects inline in the wake of the weld-pool.

This is the development of both an eddy-current T-sensor for largely eliminating spurious influences as well as a computer based testing and controlling unit for rapidly and precisely positioning the beam to the gap run. For this reason, beam wandering and fusion defects in the flank region can, to a large extent, be avoid.

Another approach is to detect relevant information about the grade and quality of the welded joint during the process sequence in order to create a new possibility for controlling the process. Quality relevant process parameters are the current energy input and the weld-pool formation. To monitor the weld-pool process online, a multichannel electron- and X-ray measuring system was developed, installed and tested. The radiation detectors are aligned via a fine double slot collimator with a port of $0,012 \mathrm{~mm}^{2}$ and using a frequency range up to $100 \mathrm{~Hz}$ provide in situ information about the energy transformation and the process response in the weld-pool region. In this way, variations in the weld-gap as well as irregularities in the weld-pool can be detected online during the welding of the mating parts and can be used to rapidly control the process.

Regarding rapidly recognising defects in the process sequence online, a remote field eddy-current technology was developed based on FEM-simulated computations. Using this technology, unambiguous statements can be made regarding the defect's formation and the defect's depth in the region of the weld-seam for thick-walled components via the signal's amplitude and phase.

Concerning stress-designed fabrications of modern components, investigations were carried out within the framework of the CRC 675 "High strength, locally modified components and structures" to locally set directionally dependent component properties with respect to their loading profile via global work-hardening and local work-softening. With regard to this, global work-hardening can be achieved via, for example, cold work-hardening, hardening, precipitations and local work-softening by means of stress relieving, tempering recrystallisation as well as microstructural phase changes.

Beam technologies such as laser and electron beam methods are suitable for locally heat treating component edge regions. Specifically and locally setting microstructures and component properties in an edge line by avoiding material damage requires systematically adapting the beam and the processing parameters to the material, the processing procedure and the component geometry. The material properties can be directionally influenced via aligning the processing lines or their introduction into geometrical line structures. With this, new prospects emerge for adapting the component properties to the predominately asymmetric loading profiles via individually calibrated anisotropy of the material parameters.

\section{Acknowledgements}

The investigations were performed within the framework of the Collaborative Research Centre CRC 675 "High strength, locally modified components and structures" in the subproject C4. Our thanks go to the German Research Foundation for sponsoring this research project. 


\section{References}

[1] R. Zenker, A. Buchwalder, N. Frenkler, S. Thiemer: Moderne Elektronen Strahltechnologien zum Fügen und zur Randschichtbehandlung. Zeitschriftenaufsatz, Vakuum im Forschung und Praxis, Vol. 17 (2005), pp. 66-72

[2] W. Reimche, Fr.-W. Bach, G. Mroz, R. Duhm, M. Bernard, M. Diebel: High Strength 3D NonVacuum Electron Beam Weld Joints - Setting of Gradient Material Properties and Testing of Weld Quality. Steel Research int. 79, Vol. 3 (2008), pp. 225-232

[3] K. Lau, Fr.-W. Bach: Dünn- und Dickblechschweißen mit dem Elektronenstrahl an Atmosphäre. Innovationsforum „Elektronenstrahltechnologie im Maschinen- und Anlagenbau “, Burg bei Magdeburg, 07.-08. März 2007

[4] F. Eichhorn, B. Spies, P. Ritz: Fugenspalterkennung und selbsttätige Nahtfugennachführung beim Elektronenstrahlschweißen. Konferenz-Einzelbericht, XII. Schweißtechnisches Hochschulkolloquium, Haus der Technik, Essen, 22. März 1979, pp. 117-131

[5] G. Bolmsjö, M. Fridenfalk: Design and validification of a universal 6D-seam tracking system in robotic welding based on laser welding. The Industrial Robot, Band 30 (2003) Heft 5, pp. 437-448, ISSN 0143-991X

[6] M.P. Howarth, M.F. Guyote: Wirbelstrom- und Ultraschallsensoren für Lichtbogenschweißroboter. Sensor Review Band 3 (1983) Heft 2, pp. 90-93

[7] G. Ripper, K. Schmelzeisen: Elektronenstrahlschweißen von Al-Bauteilen an Atmosphäre. Konferenz-Einzelbericht, ASTK, 9. Aachener Schweißtechnik Kolloquium, 29.-30. Juni 2004, pp. 109-119, ISBN 3-8322-2840-3

[8] C. Ribton: Electron beam real-time seam tracking at $30 \mathrm{~kW}$. Zeitschriftenaufsatz, The Industrial Robot, Band 21 (1994) Heft 3, pp. 11-12, ISSN 0143-991X

[9] U. Dilthey, J. Weiser: Adaptive Strahlnachführung beim Elektronenstrahlschweißen. Zeitschriftenaufsatz, Schweißen und Schneiden, Band 46 (1994) Heft 7, pp. 339-340, ISSN 0036-7184

[10]F. Bardin, R. McBride, A. Moore, S. Morgan, S. Williams, J. Jones, D.P. Hand: Real-time temperature measurement for process monitoring of laser conduction welding. KonferenzEinzelbericht, ICALEO 2004, 23th International Congress on Application of Lasers \& ElectroOptics, Laser materials processing conference and laser microfabrication conference, 4.-7. Oktober 2004, Proceedings Vol.97 (2005), ISBN 0-912035-77-3

[11]T. Müller, K.H. Gaida, K.J. Kern, G. Köhler: Erfahrungen bei der Überwachung und Steuerung von automatischen WIG-Schweißprozessen mittels digitaler Bildverarbeitung. Konferenz-Einzelbericht, Schweißen und Schneiden 99, Weimar, 12.-17. September 1999, DVS-Berichte, Band 204 (1999) pp. 239-242, Verlag für Schweißen und verwandte Verfahren, Düsseldorf, 1999, ISBN 3-87155-661-0, ISSN 0418-9639

[12]S. Böhm: Modellierung und Simulation des Elektronenstrahl-Schweißprozesses unter Berücksichtigung der Elektronenreflexion und der Elektronenstreuung. Dissertation, RWTH Aachen, 1999

[13] V. Braverman, S. Bayakin, V. Bashenko: Control over Electron Beam Welding Process by $X$-ray radiation from the zone of welding. Tagungsband, 6. Internationale Konf. Strahltechnik, Halle, pp. 68-74, 2004 
[14] J. Overrath, I. Decker, H. Wohlfahrt: Qualitätsüberwachung beim Elektronenstrahlschweißen von Aluminium-Druckguß. Konferenz-Einzelbericht, Internationale Konferenz Schweißtechnik, Werkstoffe und Werkstoffprüfung, Bruchmechanik und Qualitäts-management, Wien, 22.-24. September 1997, Proceedings, Band 2 (1997) pp. 679-687, ISBN 3-901167-04-2

[15] G. Riegert, T. Zweschper, A. Dillenz, G. Busse: Inspection of rivets and cracks in metal using thermography methods. Konferenz-Einzelbericht, 6. Quantitative infrared thermography, international conference, Dubrovnik, Kroatien, 24.-27. September 2002

[16] D. v. Dobeneck: Elektronenstrahl-Schweißen von Serienteilen der Automobilindustrie. Konferenz-Einzelbericht, ASTK, 9. Aachener Schweißtechnik Kolloquium, 29.-30. Juni 2004, pp. 121-129, ISBN 3-8322-2840-3

[17] G. Ithurralde, D. Simonet et al.: Non destructive testing in space environment. KonferenzEinzelbericht: WCNDT, World Conf. on Non-Destructive Testing, Band 15 (2000) pp. 1-9, 2000

[18] V. Wesling, U. Dilthey: Nahtgestaltung und Werkstoffreaktionen beim Elektronenstrahlschweißen von Aluminium-Werkstoffen an Atmosphäre. Abschlussbericht, Forschungsvorhaben DVS 6.034/AiF 12.752 N, Clausthal/Aachen, Juni 2003

[19] A. Yashan, R. Becker, G. Dobmann: Nondestructive testing and evaluation of materials using magnetic sensors: defect detection. Konferenz-Einzelbericht, IInd NDT in Progress Congress, Prag, Tschechien, 06.-08. Oktober 2003

[20]C. Körling: Die mechanischen Eigenschaften unterschiedlich wärmebehandelter Einsatzstähle. Dissertation, RWTH Aachen, 1989

[21]B. Gerold: Gefüge- und Eigenschaftsänderungen von FeCr-Legierungen mittels ExcimerlaserBelichtung. Dissertation, Universität Erlangen-Nürnberg, 2001

[22]R. Zenker, A. Buchwalder, N. Frenkler, S. Thiemer: Moderne Elektronenstrahltechnologien zum Fügen und zur Randschichtbehandlung. Zeitschriftenaufsatz, Vakuum in Forschung und Praxis, Band 17 (2005) Heft 2, pp. 66-72, ISSN 0947-076X

[23]C.-C. Wang, Y. Chang: Effect of postweld treatment on the fatigue crack growth rate of electron-beam-welded AISI 4130 steel. Zeitschriftenaufsatz, Metallurgical and material transactions A, physical metallurgy and materials science, Band 27A (1996) Heft 10, pp. 3162-3169, ISSN 1073-5623

[24] T. Sebastiano, D. Fabio, M. Marcello: Electron beam welding and post-weld treatments of steels. Zeitschriftenaufsatz, Journal of materials science letters, Band 15 (1996) Heft 10, pp. 827-830, ISSN 0261-8028

[25] X. Chen, J. Li, Z. Li, F. Liu: A study on local heat transfer of $18 \mathrm{Ni}$ maraging steel after electron beam welding - Eine Studie zum lokalen Wärmeübergang beim Elektronenstrahlschweißen von martensitaushärtendem 18Ni-Stahl. Zeitschriftenaufsatz, Steel research, Band 65 (1994) Heft 12, pp. 557-560, ISSN 0177-4832

[26]D. Dudek, B. Olszewska-Mateja: Zur Standzeit von elektronenstrahlgehärteten Baggerzähnen. Zeitschriftenaufsatz, Braunkohle (1991) Heft 9, Breslau, PL, '91

[27]B. Wielage, H. Pokhmursa, A. Wank, V. Wesling, A. Schram, U. Triebstein: Qualifizierung von Elektronenstrahlverfahren zur Verbesserung der Verschleißbeständigkeit von Leichtmetallwerkstoffen. Konferenz-Einzelbericht, DVS Berichte, Band 232 (2004) pp. 127-132, Düsseldorf, 2004 
[28]F. Hengerer, W. Nierlich, J. Volkmuth: Röntgenbeugung - ein bewährtes Werkzeug bei der Entwicklung, Fertigung und Bewertung von hochbeanspruchten Bauteilen. Zeitschriftenaufsatz, HTM - Härterei-Technische-Mitteilungen, Band 59 (2004) Heft 1, pp. 64-69

[29] O. Muransky, P. Lukas, P. Sittner, J. Zrnik, P. Jencus, Z. Novy: In-situ neutron diffraction studies of phase transformations in Si-Mn TRIP steel. Konferenz-Einzelbericht, 7th international conference on residual stresses, Xian, VR China, 14.-17. Juni 2004

[30]D. Maischner, A. Weisheit, K. Wissenbach: Neue Anwendungen für hochfeste Stahlbleche durch lokale Wärmebehandlung. Aachen, Frauenhofer Jahresbericht 2007

[31]Fr.-W. Bach, A. Szelagowski, R. Versemann, M. Zelt: Non Vacuum Electron Beam Welding of Light Sheet Metals and Steel Sheets. Welding in the world, Band 47, Heft 3/4, 2003, pp. 4-10

[32] G. Bolmsjö, M. Fridenfalk: Design and validification of a universal 6D-seamtracking system in robotic welding based on laser welding. The Industrial Robot, Band 30, 2003, pp. 437-448

[33]K.L. Feiste: Entwicklung der Harmonischen-Analyse von Wirbelstromsignalen zur Charakterisierung mechanischer Kugelgraphitgusseigenschaften. Fortschritt Berichte VDI, Reihe 8, Nr. 1006, Diss. Uni. Hannover, ISBN 3 18-500608-9 2003

[34]P. Petrov, C. Georgiev, G. Petrov: Experimental investigation of weld pool formation in electron beam welding. Zeitschriftenaufsatz, Vacuum, Band 51 (1998) Heft 3, pp. 339-343, ISSN 0042-207X

[35] W. Reimche, Fr.-W. Bach, G. Mroz, R. Duhm, M. Bernard, M. Diebel: High Strength 3D NonVacuum Electron Beam Weld Joints - Setting of Gradient Material Properties and Testing of Weld Quality. Steel Research int. 79, Vol. 3 (2008), pp. 225-232

[36] R. Duhm, K.L. Feiste, T. Komber, W. Reimche, Fr.-W. Bach: Online- Überwachung optimierter Speisungsvorgänge beim Schwerkraft- und Niederdruck-Aluminiumsandguss. Aluminium, Giesel-Verlag (2001)

[37] W. Reimche, Fr.-W. Bach, G. Mroz, R. Duhm: Setting of gradient material properties and quality control of high tension 3D-weld joints. Trans Tech Publications Ltd, Vol. 22 (2007), pp. 113-125

[38] W. Weber, K.L. Feiste, W. Reimche, Fr.-W. Bach, D. Stegemann: Fernfeld Wirbelstromprüfsystem zur Fehlerprüfung von dickwandigen austenitischen Rohrleitungskomponenten. DGZfP-Jahrestagung, Berlin (2001)

[39] W. Reimche, G. Mroz, M. Diebel, Fr.-W. Bach: Einstellung gradierter Werkstoffeigen-schaften und Qualitätssicherung hochfester 3D-NVEB-Schweißverbindungen. Industrie-kolloquium Clausthal „Hochfeste Strukturen“, 19.-20. November 2007 in Clausthal-Zellerfeld, pp. 191-197

[40] W. Reimche, M. Diebel, G. Mroz, Fr.-W. Bach: Einstellung gradierter Werkstoff-eigenschaften und Qualitätssicherung hochfester 3D-NVEB-Schweißverbindungen. Tagungsband 7. Industriekolloquium Clausthal „Potentiale metallischer Werkstoffe lokal nutzen“, Sonderforschungsbereich 675, Clausthal-Zellerfeld, 25.-26. November 2009, pp. $93-107$

[41] Information on http://www.sfb675.tu-clausthal.de/, Stand 26.10.2009 
[42] W. Reimche, T. Komber, K.L. Feiste, W. Weber, Fr.-W. Bach: Anwendung zerstörungs-freier elektromagnetischer Prüftechniken zur Ermittlung der Kaltverformung und Materialermüdung austenitischer Werkstoffe. Vortrag, 7. Delta-Test-Fachtagung, Celle, (2004)

[43] W. Weber: Zerstörungsfreie Prüfung dickwandiger austenitischer Rohre und Rohrbögen mit fortschrittlicher Wirbelstromtechnik. Dissertation, Dezember (2002) 